The IMPACT IMPERATIVE - Laser Ablation For Deflecting Asteroids, Meteoroids, And Comets From Impacting The Earth

J. Campbell

NASA/MSFC

C. Phipps

L. Smalley

University of Alabama, Huntsville

J. Reilly

D. Boccio

Queensborough Community College of the City University of New York

First International Symposium on Beamed Energy Propulsion Huntsville, Alabama. November 5-7. 2002 


\title{
DRAFT
}

\section{The IMPACT IMPERATIVE - Laser Ablation For Deflecting Asteroids, Meteoroids, And Comets From Impacting The Earth}

\author{
Dr. Jonathan W. Campbell \\ Advanced Space Flight Projects \\ NASA/MSFC \\ Huntsville, Alabama \\ jonathan.campbell@msfc.nasa.gov \\ Dr. Claude Phipps \\ Dr. Larry Smalley \\ Professor Emeritus, Physics \\ University of Alabama, Huntsville \\ Dr. Jim Reilly \\ Dr. Dona Boccio \\ Queensborough Community College of the City \\ University of New York
}

\begin{abstract}
Impacting at hypervelocity, an asteroid struck the Earth approximately 65 million years ago in the Yucatan Peninsula area. This triggered the extinction of almost $70 \%$ of the species of life on Earth including the dinosaurs. Other impacts prior to this one have caused even greater extinctions.

Preventing collisions with the Earth by hypervelocity asteroids, meteoroids, and comets is the most important immediate space challenge facing human civilization. This is the Impact Imperative.

We now believe that while there are about 2000 earth orbit crossing rocks greater than 1 kilometer in diameter, there may be as many as 200,000 or more objects in the $100 \mathrm{~m}$ size range. Can anything be done about this fundamental existence question facing our civilization? The answer is a resounding yes!

By using an intelligent combination of Earth and space based sensors coupled with an infra-structure of high-energy laser stations and other secondary mitigation options, we can deflect inbound asteroids, meteoroids, and comets and prevent them from striking the Earth.
\end{abstract}




\section{DRAFT}

This can be accomplished by irradiating the surface of an inbound rock with sufficiently intense pulses so that ablation occurs. This ablation acts as a small rocket incrementally changing the shape of the rock's orbit around the Sun. One-kilometer size rocks can be moved sufficiently in about a month while smaller rocks may be moved in a shorter time span.

We recommend that the World's space objectives be immediately reprioritized to start us moving quickly towards an infrastructure that will support a multiple option defense capability. While lasers should be the primary approach initially, all mitigation options depend on robust early warning, detection, and tracking resources to find objects sufficiently prior to Earth orbit passage in time to allow mitigation.

Infrastructure options should include ground, LEO, GEO, Lunar, and libration point laser and sensor stations for providing early warning, tracking, and deflection. Other options should include space interceptors that will carry both laser and nuclear ablators for close range work. Response options must be developed to deal with the consequences of an impact should we move too slowly.

\section{INTRODUCTION}

Astronomical telescopes and deep space radar systems have verified the existence of a large number of near-Earth objects (NEOs), such as asteroids, meteoroids, and comets that potentially could destroy most life on Earth.

An asteroid with a diameter of 1-10 km would strike the Earth with a power rivaling the strength of a multiple warhead attack with the most powerful hydrogen bombs known to man. This strike would throw up a cloud of dust rivaling the most powerful volcanic explosion, which could seriously affect climate on the scale of two to three years.

Computational fluid dynamics studies have indicated that an ocean strike by an asteroid this size would create a gigantic tsunami that would flood and obliterate coastal regions. More significantly, it would eject a massive dust cloud that would alter our biosphere to the point that life as we know it would cease to exist. There would be little chance of recovery within the near term.

As recent as five years ago, it was thought by the astronomical and astrophysics community that most of the known NEOs do not pose a near term threat, and therefore that these objects do not present any danger to the Earth and its biosphere. However, the relatively recent collision of the comet Shoemaker-Levy 9 with Jupiter and continuing discoveries of uncatalogued asteroids passing near Earth without any advanced warning have increased concerns. 


\section{DRAFT}

The idea presented here is to use lasers to defend against Earth impacting asteroids and comets. Although popularized in recent films, this is an important, but admittedly farreaching topic that our civilization must address now. It is worthwhile to note that one striking feature of practically every celestial body in our solar system is the abundance of impact craters. [See The Threat of Large Earth-Orbit Crossing Asteroids, $103^{\text {rd }}$ Congress, First Session, Hearing House Committee on Science, Space and Technology, Subcommittee on Space (Washington, DC: March 24, 1993), which discusses NASA and international research on detecting and deflecting asteroids before these hit the earth.]

Since collisions with asteroids, meteoroids, and/or comets have caused major havoc to the Earth's biosphere on several occasions in the geological past, one reality of our civilization's continued existence is that the Earth will experience another impact in the future.

\section{BACKGROUND}

Impacts from Near-Earth Objects (NEO's) are not "academic" problems. Direct impact by a NEO approximately $10 \mathrm{~km}$ diameter will annihilate most biota because of the resulting firestorm and nuclear winter. Such objects have a kinetic energy release of order 30TT (teratons), create tidal waves [Hills, 1992] and earthquakes.

The last such epoch-ending event occurred $65 \mathrm{M}$ years ago at the so-called "K/T boundary". The location of the impact is now known to be the Chicxulub site off the coast Yucatan [see Sharpton 1993].

An multiple body impactor of greater energies (Comet Shoemaker-Levy) struck Jupiter in 1994. Each body left a mark the size of Earth in its upper atmosphere. A more recent (and more likely) example is the Tunguska event of June 30, 1908 (Figure 1), in which an object probably $110 \mathrm{~m}$ in diameter impacted with 10MT explosive equivalent, clear cutting $2150 \mathrm{~km}^{2}$ of forest. It was probably a "snowball" NEO [BBC 2001]. NEO's include Earth-crossing Asteroids (ECA's), meteoroids and comets. 


\section{DRAFT}

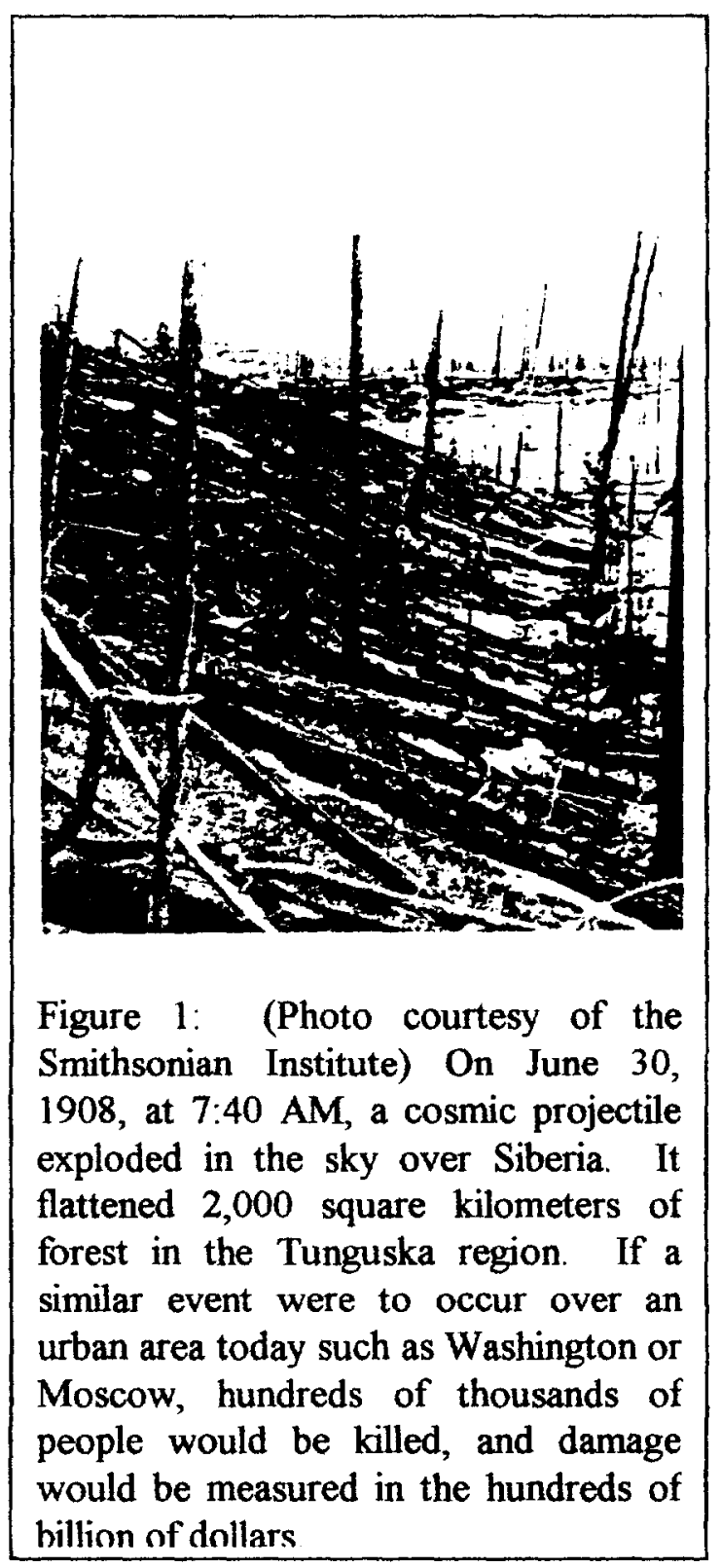

Impacting NEO's cause damage via 6 mechanisms, whose relative importance depends on site, energy, diameter and path. Only three of these require the NEO to strike land [Table 1]. 


\section{DRAFT}

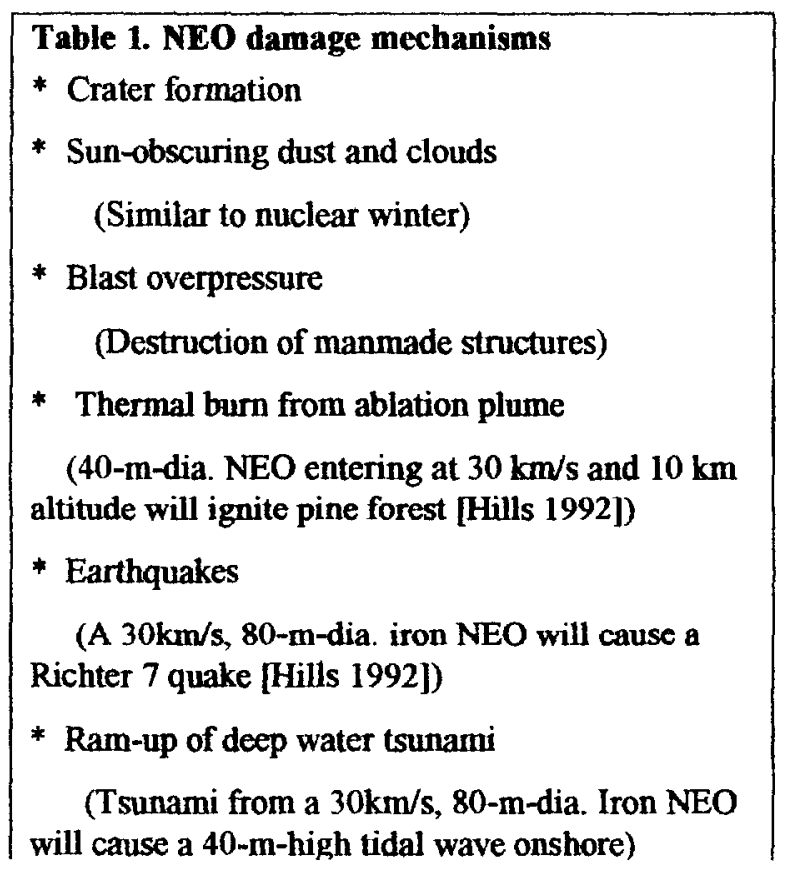

For the 10-km-size "doomsday asteroids," Earth impact frequency is about one per $100 \mathrm{My}$. However, impact probability is a strong function of asteroid diameter $\mathrm{d}$, so that NEO impacts of the size that initiated the Tunguska event happen every few centuries. Where diameter $d$ is in meters, NEO impact frequency (per year) is given by [see Shoemaker 1995 and Figure 2]

$$
N(d)=80 / d^{x} \text { where } 2.5<x<3 \quad[1]
$$




\section{DRAFT}

Each month, about 30 of these small $(40-80 \mathrm{~m})$ diameter objects pass through the Moon's orbit, offering excellent opportunities for diagnostics and experiments. Epochending NEO's have also passed within fractions of an AU in the past decade. Small NEO's are the most likely threat in our lifetime [see Eq. 1]. However, small NEO's are extremely difficult to detect in time to take action. For example, assuming detection at visual magnitude $m_{V}=23$; an $80-m$-diameter, $30 \mathrm{~km} / \mathrm{s}$ "dirty snowball" $N E O$ with albedo 0.025 will be 200 light-seconds distant $(0.4 \mathrm{AU})$ on detection and just 23 days from Earth impact.

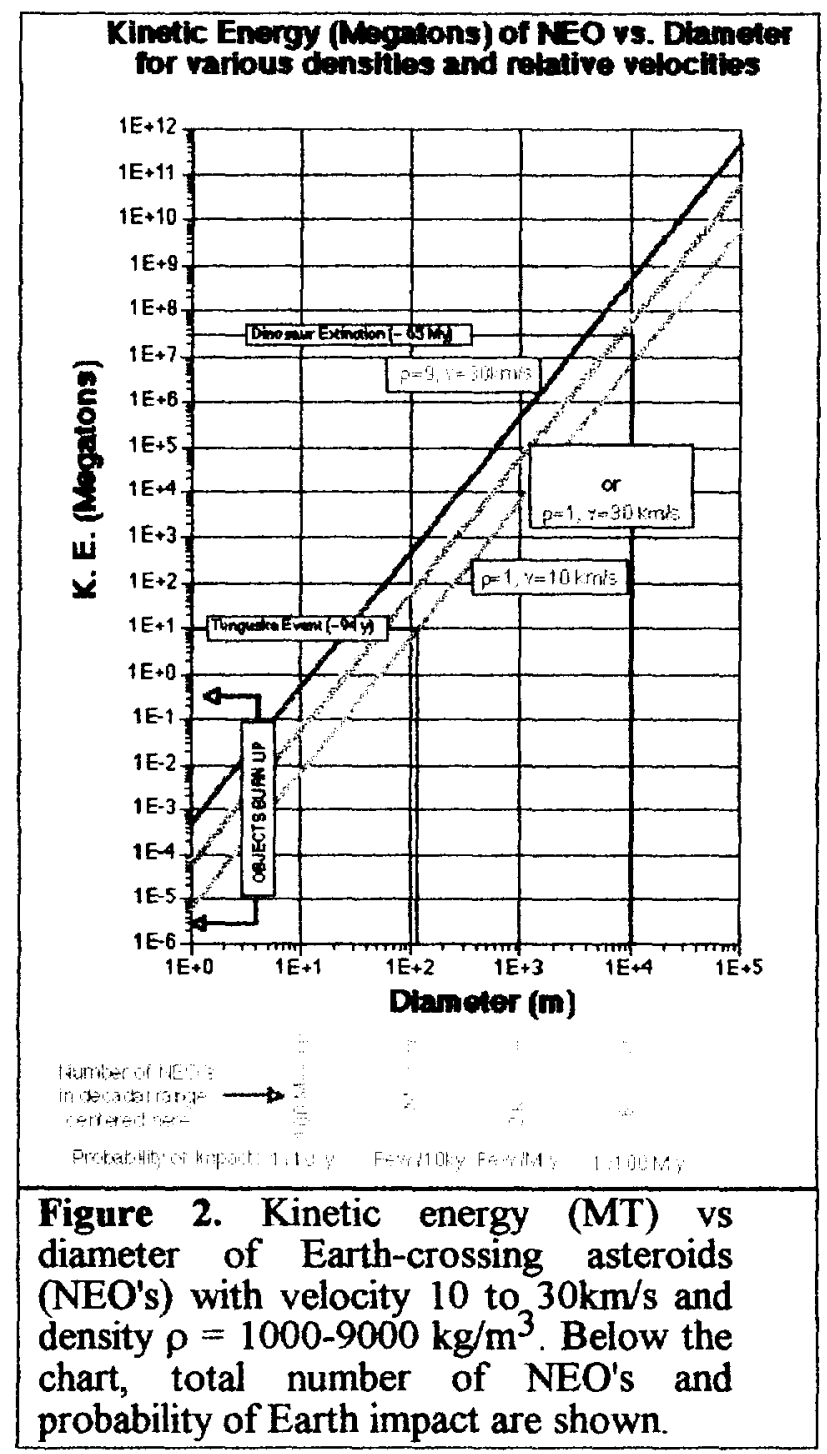

Nuclear deflection has been suggested [Solem 1993]. In this approach, a multi-MT weapon is detonated in the vicinity of, but not adjacent to, the NEO. Orbit modification occurs through rapid ablation of the object as opposed to gradual ablation from the laser approach. Considering the additional time required to verify orbit, 23 days leaves 


\section{DRAFT}

inadequate time for launching any kind of nuclear-tipped conventional interceptor, transporting the payload to the NEO, and matching its speed (in the reverse direction) and detonating optimally.

In contrast, laser deflection offers instant response, agility, and low cost compared to the nuclear alternative. Lasers do not have to be transported to the target. Laser deflection is also attractive relative to putting nuclear weapons in orbit, a suggestion that may not be embraced by the general public. Laser deflection uses the thrust produced by a jet produced on the surface of the NEO by laser ablation [Phipps 1992-5, 1997-8].

Because of the NEO's speed, deflection is only possible if this energy is delivered starting at a great distance. There is a quadratic effect here: the velocity change required to miss the Earth increases with decreasing time to collision, and decreasing time to act requires proportionally more power to achieve the same velocity change. Consequently, even if the laser spot diameter is never larger than the NEO, required laser power increases quadratically with decreasing range at detection:

\section{LASER PUSHING}

In essence, the intensity of the laser must be sufficiently great to cause the material on the surface of the object to ablate. As the resulting hot vaporized material expands, a reactive force (or thrust) is imparted to the object. For a given material and duration of a laser pulse there is an optimum intensity for coupling of laser energy into the material. Higher intensity's are no help because the resulting ionization of the vapor from the material effectively absorbs the additional energy.

Coupling is considered strong when the intensity reaches at least one tenth of the optimum intensity. The optimum intensity scales roughly as the square root of the pulse duration. Pulses with a modest energy and average power may have a high intensity if the pulse duration is short.

The Orion study considered laboratory experiments that were conducted with representative materials, and found useful models of the coupling of metals and nonmetals. An example is shown in Figure 3.

The optimum intensity is higher for metals than for nonmetals, since energy tends to be conducted to the interior of the metal. However, at higher intensities, the coupling is higher for metals than for nonmetals. This is because the onset of plasma formation above the optimum intensity for nonmetals occurs at lower intensities. The peaks of the curves of Figure 3 are at the optimum intensities for $5 \mathrm{~ns}$ pulses, and the optima are at higher intensities for longer pulses. For example, the vertical marks in the figure are the range of intensities calculated for a system with only a $20 \mathrm{~kJ}, 5$ ns pulsed laser at $1.06 \mu$ 


\section{DRAFT}

directed by a $3.5 \mathrm{~m}$ aperture onto a target in a $500 \mathrm{~km}$ circular orbit as the zenith angle varies from 0 to $60^{\circ}$.

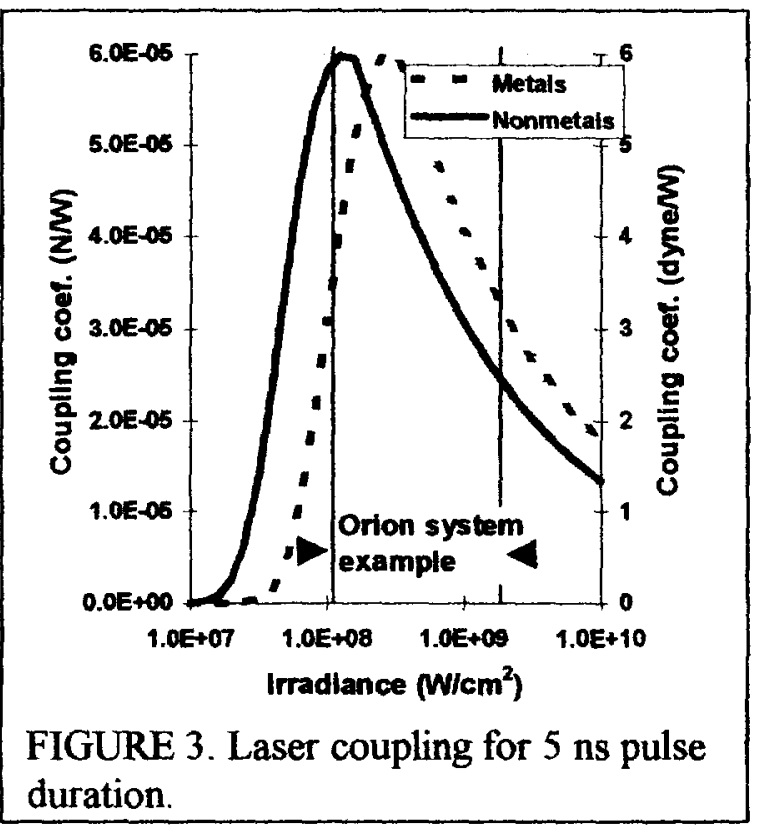

\section{ADAPTIVE OPTICS}

For laser stations on the Earth's surface, adaptive optics would be required to operate through the atmosphere.

For example, we know from the Orion study that useful laser deflection results from placing instantaneous intensities on the order of $10^{8}\left(\mathrm{~W} / \mathrm{cm}^{2}\right)$ on the target. With a high pulse energy of $20 \mathrm{~kJ}$, short pulse duration of $5 \mathrm{~ns}$, and range of $1600 \mathrm{~km}$, the angular diameter required is $1.4 \mu \mathrm{rad}$. Without adaptive optics, small-scale turbulence in the atmosphere spreads the beam to an angular diameter on the order of $10 \mu \mathrm{rad}$. Also, turbulence on larger scales tends to tilt the wavefront and displace the emerging beam from its intended path.

High-order correction for atmospheric turbulence has been demonstrated with laser guide stars and active optical correction. At the USAF Phillips Laboratory Starfire Optical Range (SOR), for example, resolution better than $1 \mu \mathrm{rad}$ has been obtained at $0.85 \mu \mathrm{m}$ with a $1.5 \mathrm{~m}$ aperture (Starfire Optical Range 1997).

The image shift due to large-scale turbulence can be measured by the shift in the apparent position of a star from its expected position. It is impractical, however, to use stars for a ground based, asteroid deflection system, since there is not enough integration time available for faint stars, especially during daytime with competition from scattered sunlight. The light from a laser guide star traverses the same path as the 


\section{DRAFT}

original laser, and hence is not useful for determining the wavefront tilt. At the Steward Observatory, for example, tilt correction was accomplished for the MultipleMirror Telescope (MMT) with a field star $200 \mu \mathrm{rad}$ from the laser guide star (Center for Astronomical Adaptive Optics 1997).

Two key points relative to the adaptive optics remain to be investigated. First, since it is desirable to operate a future laser station at all times of the day, the requirements for adaptive correction during the daytime must be investigated. During the daytime, atmospheric turbulence increases and makes the adaptive optics more difficult.

A laser technology demonstration will be needed to determine to what extent the Fried scale of the turbulence decreases, and whether multiple guide stars will be needed for daytime operation. The second point to be investigated is how large the zenith angle can be while still maintaining good compensation. As we discuss below, it is desirable to reach 60 degrees from the zenith. The smaller apparent angular speed of the target at larger zenith angles will work to an advantage.

\section{ASTEROID AVOIDANCE SYSTEM}

Many schemes have been discussed for dealing with NEOs on collision courses with the earth. These include the use of nuclear weapons to fragment the NEO, or landing on them using various methods (propulsive, explosive, etc.) to steer the asteroid into a passing orbit.

Fragmentation may not be a viable solution because the center of mass of the cloud would continue on the original collision trajectory as the parent mass. This would result in multiple impact events similar to the Shoemaker-Levy 9 collision with Jupiter. Also, fragmentation may make subsequent orbit shaping more difficult.

Many issues and engineering solutions need to be addressed in order to land on a NEO and place nuclear devices or other trajectory altering systems there. Although the cost of any NEO protection system will likely be significant, any system requiring a deepspace rendezvous would also require sufficient warning of an impact to be implemented. Additionally, a failure of such a defense system may not allow for a second mitigation effort to be attempted before the object impacts the Earth.

A better system would be one that is "on station" and could be used routinely to shape asteroid orbits over long periods of time so that they do not pose a potential threat. The system should also be able to handle the wide range of materials and sizes that constitute the NEO population (current or yet to be discovered). Phased Array Laser Systems (PALS) could be developed and placed in space, either orbiting or lunar based. Space-based laser constellations (SBL) are presently under development and will be 


\section{DRAFT}

flown during the next decade. The feasibility for a PALS based system is discussed below.

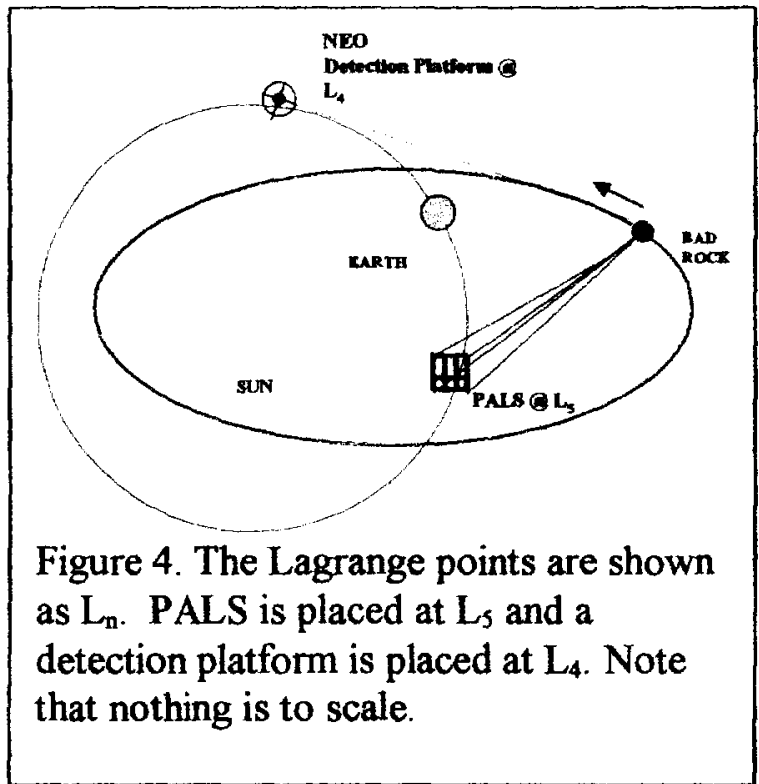

Laboratory experiments using a $20 \mathrm{~kW}$ pulsed laser have shown that the impulse imparted to aluminum targets due to the ejected plasma cloud gives an average surface pressure $p=6.5 \times 10^{-4} \mathrm{~N} / \mathrm{cm}^{2}$, or equivalently, an acceleration $\mathbf{a}=1.25 \times 10^{-6} \mathrm{~m} / \mathrm{s}^{2}$.

Thus, with present technology, an array of laser beam directors can be aimed at an asteroid, meteoroid, or a comet, providing sufficient power to ablate its surface. It is simply a matter of putting in place a sufficient number of lasers to accomplish the mission.

To generate ablation thrust, the main requirement is that the minimum laser intensity

$$
I \min =24 / \tau^{0.55} \mathrm{~kW} / \mathrm{cm}^{2}[2]
$$

be delivered the NEO surface, either during a pulse or continuously. A laser momentum-coupling coefficient (thrust to optical power ratio)

$$
\mathrm{C}_{\mathrm{m}}=\mathrm{F} / \mathrm{P}=50 \mathrm{~N} / \mathrm{MW}
$$

can be assumed [Phipps 1997].

Deflecting a $1 \mathrm{~km}$ diameter iron asteroid, as we will see in the simulation results that follow will require a peak laser power of approximately $200 \mathrm{GW}$. Several alternate potential approaches are available to power the array including nuclear or electric generation and solar power arrays. 


\section{DRAFT}

Let us assume that the asteroid is at infinity moving toward the Earth with a closing velocity $v_{0}$. The closest point of approach $R_{e}$ is given by

$$
R_{e} \cong R_{E}\left[1+2 g\left(\frac{R_{B}}{v_{0}^{2}}\right)\right]^{\frac{1}{2}}
$$

where $R_{E}$ is the radius of the Earth, and $g$ is the gravitation acceleration at the surface of the Earth. Clearly, for the large anticipated values of $v_{0}$, the Earth's gravitational pull will be insignificant in the encounter. There are two cases of interest:

- "Head-on" collision:

$$
v_{o}=40 \mathrm{~km} / \mathrm{s} \longrightarrow \mathrm{R}_{\mathrm{e}}=1.04 \mathrm{R}_{\mathrm{E}}
$$

- "Catch-up" collision:

$$
v_{o}=5 \mathrm{~km} / \mathrm{s} \longrightarrow \mathrm{R}_{\mathrm{e}}=1.1 \mathrm{R}_{\mathrm{E}}
$$

Hence, we may define a threshold for success for the two possible encounter scenarios. Table 2 provides the results of a two dimensional orbital mechanics simulation looking at an encounter with a $1 \mathrm{~km}$ spherical iron asteroid and gives the final displacement at the Earth as a function of the amount of time the laser works on the object.

Table 2 shows that a minimum of 38.8 days of illuminating the target is necessary for the case of a head-on collision, and in most cases would take much less illumination time. The warning time of impending impact is of critical significance, which highlights the importance of deep space surveillance of NEOs in addition to long-term monitoring and orbital calculations.

Early orbit shaping should be extraordinarily effective using a PALS. Also it is important that PALS be deployed at positions that are allow sufficient target illumination time to properly alter the trajectory of a confirmed impactor.

Clear seeing by space-based optical telescopes (i.e., the surveillance of small, dark objects such as asteroids) is greatly improved by the absence of stray light such as that reflected from the Earth or Moon. This fact would make it desirable to place a detection system far from these disturbances. 


\begin{tabular}{|l|l|l|}
\hline $\begin{array}{l}\text { Time (in } \\
\text { days) }\end{array}$ & $\begin{array}{l}\text { Displacement } \\
\Delta \mathrm{R}\end{array}$ & $\begin{array}{l}\text { Final lateral } \\
\text { Velocity } v_{f}\end{array}$ \\
\hline $1.0 \mathrm{~d}$ & $4.9 \mathrm{~km}$ & $0.11 \mathrm{~m} / \mathrm{s}$ \\
10.0 & $485.0 \mathrm{~km}$ & $1.08 \mathrm{~m} / \mathrm{s}$ \\
36.0 & $1.00 \mathrm{R}_{\mathrm{E}}$ & $4.07 \mathrm{~km} / \mathrm{s}$ \\
38.8 & $1.10 \mathrm{R}_{\mathrm{E}}$ & $4.19 \mathrm{~km} / \mathrm{s}$ \\
44.0 & $1.45 \mathrm{R}_{\mathrm{E}}$ & $4.75 \mathrm{~km} / \mathrm{s}$ \\
46.3 & $1.56 \mathrm{R}_{\mathrm{E}}$ & $5.00 \mathrm{~km} / \mathrm{s}$ \\
\hline
\end{tabular}

However, it is also advantageous for the PALS to be located sufficiently near the Earth that it is designed to protect. One candidate is one of the Sun-Earth Lagrange Points at which a spacecraft will maintain a fixed position with respect to the Earth. Another candidate location would be the lunar far side or the lunar poles that offers excellent seeing for astronomical observations and close proximity to the Earth for the PALS.

In Figure 4, we pictorially described an asteroid encounter with the Earth and a Lagrange Point based PALS. This orbit lay between the orbits of Mars and Venus, and is consistent with the recent news that an asteroid passed between the Earth and the Sun. Better data significantly altered the prediction of closest point of approach to $1,000,000 \mathrm{~km}$ with no significant threat in the foreseeable future. Nevertheless, the orbital period of an asteroid lying between Mars and Venus is roughly $0.9 \mathrm{yr}$.

If the collision scenario depicted in Figure 4 was encountered. The PALS firing with a good aspect from $L_{5}$ and sufficient lead time (as shown in the figure,) would have 2-3 months to move the asteroid away from a collision path with the Earth. Only with a sufficiently capable detection system would there be adequate time in advance, as shown in Table 2, for the PALS to deflect the asteroid away from the Earth. This fact stresses the need for coupling with PALS an early warning system using optical and/or radar imaging techniques.

In another simulated scenario, the undetected asteroid could be chaotically ejected from the asteroid belt. In this case it is possible to describe similar results as depicted in Figure 5. In this case, the calculation is simplified by assuming that the entire impulse to the asteroid is given in one instant.

The $\Delta V$ of $5 \mathrm{~km} / \mathrm{s}$ (see Table 2) is an obvious example of an impulse that yields a "miss distance." In this case, the simulation yields that the asteroid passes in front of the Earth by 1.25 Earth diameters. 


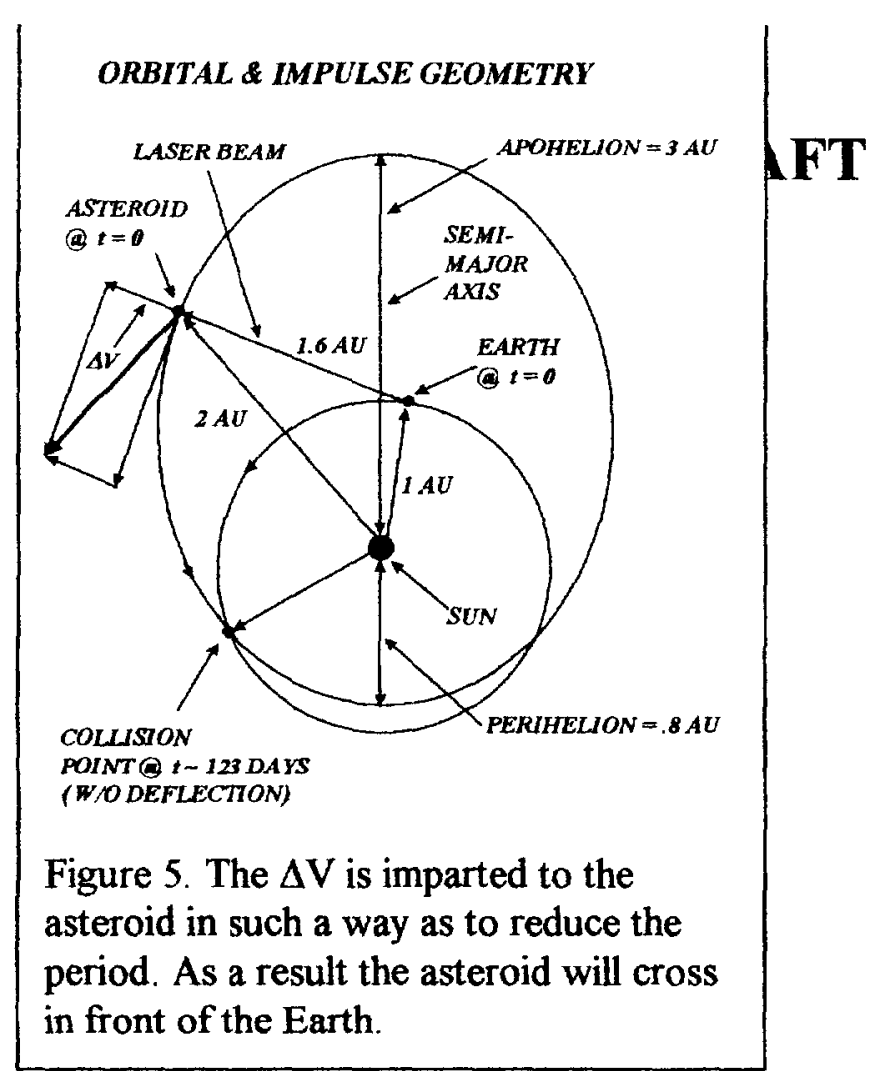

An approach requiring significantly less power for PALS would be a gradual shift in the orbit by a long duration, low intensity impulse. This lower energy impulse would reshape the orbit over a long time period, perhaps several orbits. Ideally, for the asteroidal orbit shown in Figure 5, it might conceivable to move the asteroid into an orbit that removes any potential threat to the Earth.

From a non-defensive standpoint, it is interesting to contemplate asteroid orbit modification for the purpose of scientific exploration and/or commercial exploitation (i.e., asteroid mining). This application of a PALS may be particularly feasible for small asteroids (less than $100 \mathrm{~m}$ ) in orbits that are "easily" modified to a desired rendezvous location for processing.

Additional considerations are illustrated in the two cases illustrated in Figure 6, the NEO is approaching Earth at $30 \mathrm{~km} / \mathrm{s}$, and has been discovered at a range of $1000 \mathrm{Lt}-\mathrm{s}$ ( 1 A.U.), giving about 120 days for response. Two positions of Earth ( $E_{1}$ and $E_{2}$ ) and of the NEO [(1) and (2)] are shown at times 48 hours apart. In the case II scenario, observers using telescopes on opposite sides of Earth make simultaneous measurements of the NEO angular position with a precision \pm 0.2 arc seconds, and determine range as $1000 \pm 23 \mathrm{Lt}-\mathrm{s}$. This error, which is about equal to the $17 \mathrm{Lt}$-s relative motion of the NEO during 48 hours, gives about 1 radian uncertainty of the NEO's vector direction during the first 48 hours after discovery. To refine this measurement down to the level needed to predict whether the NEO will miss the Earth will take an additional month. 


\section{DRAFT}
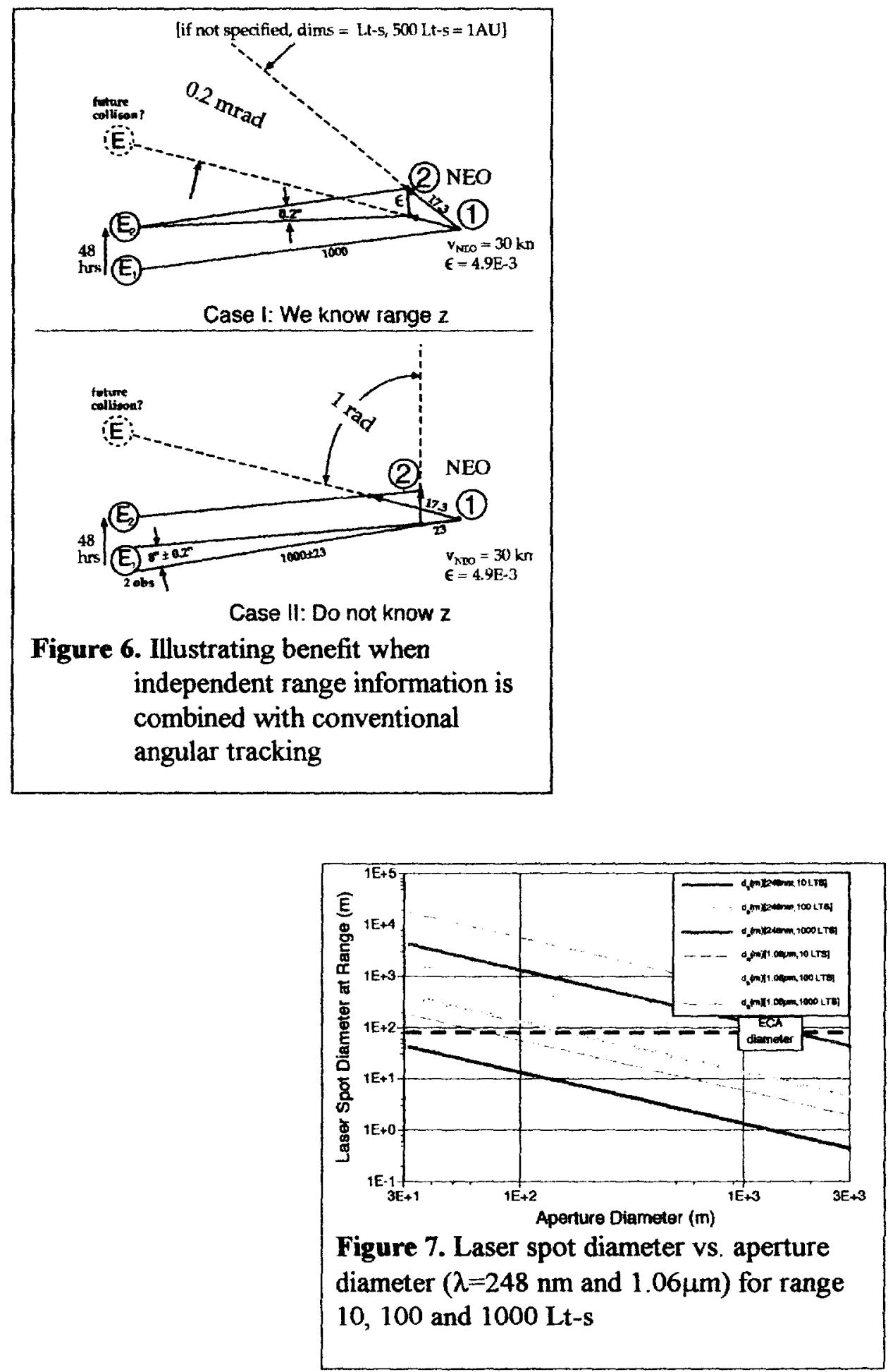

In the case I scenario, the same observations occur with the addition of tightly constrained range due to the laser or radar range measurement. With this constraint, the 


\section{DRAFT}

NEO's vector direction uncertainty is reduced to $200 \mu \mathrm{rad}$. At a range of $1000 \mathrm{Lt}-\mathrm{s}$, the future location of the NEO at closest approach has now been refined to about 5 Earth diameters during 48 hours of observation.

\section{PRASED ARRAYS}

In previous studies, the conceptual difficulty has been that making a laser spot as small as

the NEO at this distance requires a mirror of order $3 \mathrm{~km}$ in diameter [Figure $7 \&$ Phipps 1996].

With smaller mirrors than this, the spot spills over the NEO, wasting most of the laser power over exactly that portion of the NEO's travel in which thrust should be applied, and further failing to deliver the intensity required by equation [2] unless pulse width is drastically shortened. The spot size is inversely proportional to wavelength, making very short wavelengths, e.g., $\mathrm{KrF}$ at $248 \mathrm{~nm}$, highly desirable.

A sparse phased array of lasers is analogous to the Very Large Array (VLA) in New Mexico. Several widely spaced laser apertures are phased together so that their wavefronts emerge in perfect mutual phase. In the "far field", i.e., a distance much larger than the laser separation, the result is a diffraction pattern in which the central spot retains a useful fraction of the total beam energy in a spot diameter which is nearly the same as that which would come from a single mirror with diameter equal to the array diameter.

\section{EARTH OPERATIONS}

A laser array may be located on the Earth providing operations through the Earth's atmosphere is managed appropriately. For example, Stimulated Raman Scattering (SRS) will tend to limit the propagating intensity. Second, adaptive optics and laser guide stars are required to counter atmospheric scintillation.

\section{CURRENT STATE OF THE ART IN LASER AND BEAM DIRECTOR TECHNOLOGIES}

The US Air Force Airborne Laser (ABL) is a major weapon system development by the United States Air Force to provide an airborne, multi-megawatt laser system with a state-of-the-art atmospheric compensation system to destroy enemy theater ballistic missiles at long ranges [Lamberson 2002].

The Space Based Laser (SBL) program will use a high-energy laser to destroy boosting missiles in flight. The principal kill mechanism is to cause mechanical weakening of the booster skin, so that internal pressures will cause the missile to explode while it is still boosting [Riker 2002]. 


\section{DRAFT}

Both are examples of very high power lasers which are available now, and which could be deployed for preliminary asteroid thruster tests without much further development.

\section{CURRENT STATE OF THE ART IN SENSOR TECHNOLOGIES}

In general, acquisition of remote objects for observation and tracking is accomplished by the observation of either self-emitted or reflected optical energy, RF energy, acoustic energy or other quanta in comparison to some background level. In particular, only optical and radar sensors are usable to acquire targets at long range. The three approaches below are ones that currently appear to even have a chance; given the ranges, object sizes and sensor characteristics involved.

The first is microwave radar with characteristics similar to the MIT/LL HAYSTACK, DoD PAVE PAWS or DEW Line radars, but with a very-much-higher-power electronically scanned beam (repeated linear two-dimensional scan or other acquisition strategy) for wide-angle search at long range.

The second is a passive optical system - an astronomical-class telescope perhaps with an angle-scanning capability along the lines suggested by MIT/LL in the NASA ORION study for a modified HAYSTACK-type, DoD PAVE PAWS type or DEW Line type radar. The illumination of the objects would be by sunlight. The size of the instantaneous Field of View of the system fixes the instantaneous spot size being viewed, while the angle-scanning capability determines the search Field of Regard. Ecliptic Plane as well as out-of-plane threat asteroid objects must be considered.

The third is an active illuminator laser-radar (LADAR) ranging system. Economy dictates that if this option were chosen, the transmitter would use the pusher laser as the energy source, but would use a de-focused beam to interrogate a large spot in space for the detection function. The beam would be then be narrowed to perform the ranging and tracking functions.

In the sections below, we sketch the driving parameters for each of the above approaches, and suggest approaches to acquire and track the target astronomical objects that will be examined in the proposed study.

\section{SUMMARY OF ALL-RADAR ACOUISITION APPROACH}

The all-radar approach was extensively analyzed during the course of the first phase of NASA's ORION program. In that study, a radar system with beam parameters similar to those existing at the MIT/LL HAYSTACK facility was required for detection, 


\section{DRAFT}

acquisition, identification, track and handover of $2 \mathrm{~mm}-2 \mathrm{~cm}$ diameter near-earth orbital debris objects to the "pusher" laser system.

The ORION study [Campbell, 1996] recommended that another approach to the use of a radar be considered to dramatically increase the orbital debris detection rate: that of a static "picket fence" or a dynamic-motion "bow-tie" sky-scan pattern rather than a stationary staring beam be used, along with a longer pulse, to increase the measurement area from a single-beam $1 \mathrm{~km} \times 100 \mathrm{~km}$ area to one with $10 \mathrm{~km}$ (or more) $\times 100 \mathrm{~km}$ area. Since threat objects could approach Earth in both the Ecliptic plane as well as outof-plane, the search for such threat asteroid objects must be considered as a 3-D problem.

\section{SUMMARY OF COMBINATION PASSIVE OPTICAL/LADAR/RADAR ACQUISITION SYSTEM}

An effective approach to detecting the NEO uses a CCD-equipped, very-large-aperture, wide field of view (FOV) telescope and solar illumination, augmented by a "laser searchlight" or high-peak-power radar system.

The wide FOV unit enables detection in a time short compared to the time to act. In the ORION study [Campbell, 1996] it was realized early that "the sky is big". That is, although the signal-to-noise ratio of a searchlight beam is very high, the probability of finding a small-cross-section object at all is very low. This discrepancy increases as the cross-section of the target object decreases. A searchlight beam cannot scan the whole sky with any chance of accidentally discovering the NEO before it is upon us. In order to scan the ecliptic $+1-20^{\circ}$ for objects with 100Lt-s range in 2 months at a laser repetition rate of $1 \mathrm{~Hz}$, we need a spot size at range of order $100,000 \mathrm{~km}$ and, for a 80 m-diameter NEO with $16 \%$ reflectivity, using a 10-m-diameter transmitting/receiving aperture, we will need $1 \mathrm{PJ}$ laser pulses at $530 \mathrm{~nm}$ to receive one returned photon. The radar case is much better in this regard, because there are more photons per joule, but still requires $50 \mathrm{GJ}$ pulses for a single returned photon.

The searchlight's ideal function is to be used as a searchlight. The passive optical system (POS) locates the object using reflected sunlight and then the searchlight beam, narrowed down to the position uncertainty of the POS, provides range. Used together, the two systems combine the best features of each. As indicated earlier, the searchlight beam and the pusher laser beam should be one and the same.

\section{ALL-ELECTRIC SEALED-OFF GAS LASERS AND LASER ARRAYS}

The use of medium-power industrial and medical lasers (100-1000 watts average power) and much higher power (the Airborne Laser -ABL- and the Mobile Tactical High Energy Laser-MTHEL) Defense Dept laser systems have become accepted over the past few years. While industrial laser-base material processing is dominated by $10-$ 


\section{DRAFT}

micron $\mathrm{CO}_{2}$ gas lasers and 1.06 and 0.67 micron solid-state lasers, there is growing interest in the dual use of ultra-compact rugged high-efficiency lasers for commercial (medicine, wavelength-specific photochemistry) and for Defense (ship self-defense) applications in other wavelength regions. Recent advances in wave-guide array laser technology promise efficient production of high power laser emission at the wavelengths necessary for these uses, making complete fielded laser packages small, rugged, practical and economical.

In addition, electrically powering the laser's ultra-compact gain medium allows active real-time control of the output waveform from $\mathrm{CW}$, to short-pulse/high rep-rate to long-pulse/low rep-rate operation, and even intra-pulse output power temporal profiling.

A new high-power laser technology, sealed-off cooled no-flow rare gas lasers, show promise of providing line-selected operation in the 0.5 -to- 2.0 micron wavelength region with a single near-diffraction-limited output beam (using a phase-coupled folded array of waveguide gain media) and with selectable rep-pulse and CW waveforms (determined purely by the power input electrical waveforms).

Waveguide-array technology offers a novel approach to combining a sealed-off long-life gaseous electrical discharge gain medium, a laser resonator and an optimum thermal management system to create a sealed-off, compact, rugged and lightweight, maintenance-free high-power laser system.

NST, the USAF / AFRL and its industrial team members are currently engaged in a full exploitation of waveguide laser technology, for both DoD and commercial applications at wavelengths from 0.5 through 10.6 microns, and is in a unique position to evaluate this new all-electric sealed-off laser technology for NASA initiatives such as the

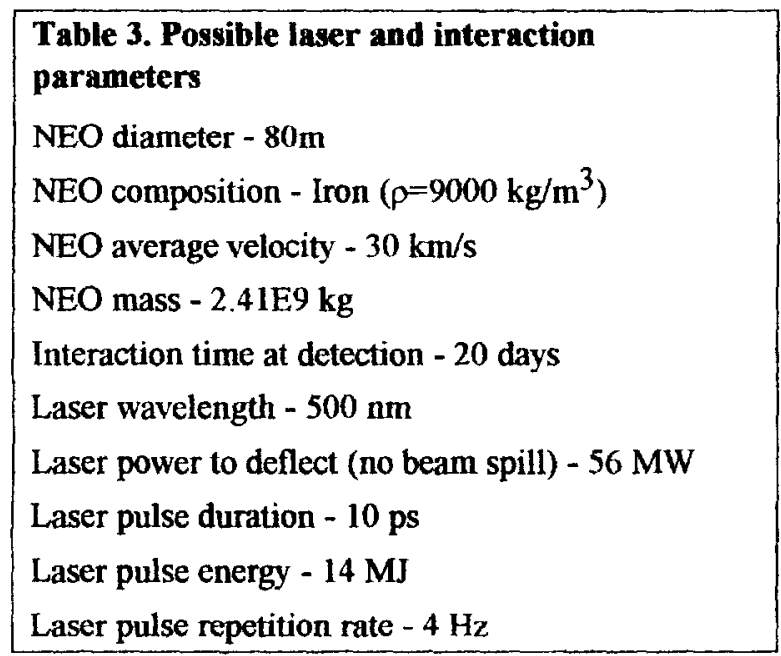

asteroid deflection application. 


\section{DRAFT}

\section{VISION: LASER SYSTEM IN SPACE DEFLECTING NEO'S}

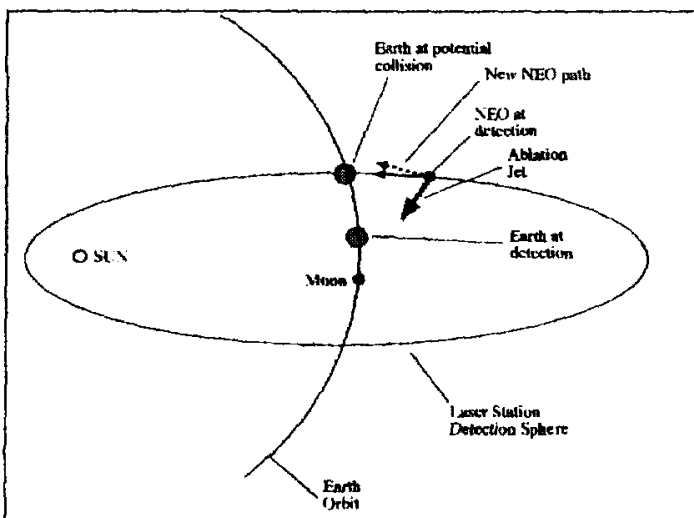

Figure 8. Cross-section in the ecliptic plane (not to scale) showing laser station. At least 5 stations on the Moon provide omnidirectional coverage. The NEO is handed off from one to the other during the interaction. Detection at $0.2 \mathrm{AU}(100 \mathrm{Lt}-\mathrm{s})$ gives at least 20 days action time. Electrical power for the lasers is beamed up from Earth.

Figures 4 and 8 illustrate our vision of a space-based laser system detecting and deflecting NEO's. At least 5 laser stations are employed, each with its own detection, ranging and laser thrust system. The moon is a necessary base to provide impulse reaction. Possible laser parameters are listed in Table 3. Note the short pulse duration that is required to ignite plasma on the $80-\mathrm{m} \mathrm{NEO}$. This beam could not pass through Earth's atmosphere!

\section{AN APPROACH FOR GETTING STARTED}

This approach should be a three-phase program (study, test, demonstration) and consist of the following elements:

a) Operational option comparisons -

b) Laser technology options comparison;

c) and sensor technology options comparison.

\section{TECHNICAL OBJECTIVES}




\section{DRAFT}

The broadly stated technical objectives of the study proposed in Phase I should be:

Define the laser and pointer-tracker (PT) system's characteristics including capabilities of the laser and PT system that a potential Phase II test planning might require for thrust and impulse-production applications. This definition must be the first objective accomplished, since it sets the technical environment for the tasks in the rest of the program.

Complete the conceptual design for a rare-gas laser system (0.3-1 micron wavelength) and solid-state system (0.3-1 micron wavelength) that satisfies the requirements of the potential application as defined above.

Identify, characterize, prioritize and select laser parameters including wavelengths in repped-pulse operation, specific wavelengths, and range of gain medium options proven reliable, as obtained from ongoing test programs and analyses.

Adapt laser designs including solid-state and sealed-off gas laser designs to be compatible with the empirically determined laser operation envelope into a preliminary design of the solid-state cooled laser and the sealed-off cooled rare-gas laser.

With the concept for a solid-state and a sealed-off waveguide-array rare gas laser in place at the end of Phase I, the logical continuation into Phase II would be first the testing of the chosen waveforms and wavelengths on appropriate materials and objects to validate impulse and thrust production. Those options that survive Phase I scrutiny will then be tested in Phase II, optimized to satisfy the requirements of the Phase II and Phase III demonstrations.

Compare sensor technology options. Geometry and sensor technology will be studied in combination to determine the best approach. Areas of investigation will include backilluminated CCD's, crossed photon-counting delay lines and other novel options.

Compare location options.

Moon - The Moon has strong advantages: providing a reaction mass for the station is critical. Disadvantages include wide temperature extremes.

Libration Points - These offer advantages and should be considered as well.

Earth - The most convenient location and least expensive superficially. Must overcome problems working through the atmosphere.

Mars - Mars is interesting as an early-warning outpost.

Rendezvous - Taking a smaller pusher laser to the target may be another option.

Examine Energy-gain Options. Study creative options for providing substantial energy gain in the laser-NEO interaction. Two of these are: a) the billiard-ball option, in which a small NEO is deflected into the path of the larger one at distance sufficient for most of the resulting fragments to clear Earth and b) the scattering option, in which the orbit of a NEO which is substantially similar to Earth's orbit is modified using Earth's gravitational field. 


\section{DRAFT}

The impact of cost sharing should be considered. Other applications can support the cost of a NEO-deflection laser system. These include capturing small asteroids and mining their rich rare-metal deposits [Blacic 1993] and deflecting Earth-orbiting space junk so that it burns up in the atmosphere [ORION concept: Phipps, et al. 1996; Campbell 1996].

\section{ACKNOWLEDGEMENTS}

The authors would like to acknowledge the outstanding contributions of Dr. Claude Phipps and Dr. James Reilly to this paper and in promoting a greater awareness of advanced laser applications in a number of critical areas.

\section{SUMMARY, CONCLUSIONS, AND RECOMMENDATIONS}

An elegant, cost effective, feasible laser technology approach has been identified - a global solution to solve a global problem. This solution is truly international in scope in that it solves the problem for everyone.

If a high energy, laser pulse of sufficient intensity strikes an asteroid, meteoroid, or comet in space; a micro-thin layer of material is ablated from its surface. This super hot vapor rapidly expands outward imparting a tiny amount of force to the object. Since current laser technology produces 10 to 100 pulses per second, the ablation interaction is rapidly repeated over and over again. This cumulative thrust acting on the object if applied at the appropriate point in the object's orbit is sufficient to deflect it from impacting the Earth.

In addition, the additional promise of orbit shaping capability for asteroids, meteoroids, and comets is that the orbit may be modified sufficiently to make it convenient for utilization such as mining or in situ materials utilization. One final note on statistics in an investment context: the probability of the Earth being struck by a hazardous asteroid in the near future is approximately a thousand times more likely than winning a recent Florida lottery.

We recommend a two-year program that will take these concepts to laboratory demonstration level as regards laser performance, laser-target interaction, detection and a lab-scale test of phased array performance.

We further recommend a follow-on program that will consist of an experimental program to prove the concepts at significant range, including detection of remote objects and pushing surrogate targets released by the Shuttle. This program will include a test in which an existing very high power laser (e.g., HELSTF, ABL, ) is employed to illuminate and measurably push one of the 30 or so 40-m-size NEO's that pass through the Moon's orbit each month. 


\section{DRAFT}

In general, we recommend that the World's space objectives be immediately reprioritized to start us moving quickly towards a multiple option defense capability an integrated ground and space infrastructure. While lasers should be the primary approach, all mitigation options depend on robust early warning, detection, and tracking resources to find objects sufficiently prior to Earth orbit passage in time to allow mitigation.

Infrastructure options should include ground, LEO, GEO, Lunar, and libration point laser and sensor stations for providing early warning, tracking, and deflection. Other options should include space interceptors that will carry both laser and nuclear ablators for close range work. Response options must be developed to deal with the consequences of an impact should we move too slowly.

Preventing collisions with the Earth by hypervelocity asteroids, meteoroids, and comets is the most important immediate problem facing human civilization. This is the Impact Imperative.

\section{REFERENCES}

1. BBC News Online, 30 October 2001

2. Center for Astronomical Adaptive Optics http://athene as arizona edu: $8000 / \mathrm{caao} /$.

3. Starfire Optical Range (1997) http:/wwwsor plk af mil/.

4. Cleghorn, George et al (1995) Orbital Debris: A Technical Assessment, National Academy Press, Washington, DC, http//www. nas. edu/cets/aseb/debris 1 html.

5. Blacic, J., "Mining Near-Earth Objects for Resources to Benefit Earth", Los Alamos National Laboratory internal white paper (1993)

6. Campbell, J.W., Project ORION: Orbital Debris Removal Using Ground-Based Sensors and Lasers, NASA Marshall Spaceflight Center Technical Memorandum 108522(1996) http://infinity.msfc nasa gov/Public/orion/default.html.

7. Hills, J. G., "Fragmentation of Small Asteroids in the Atmosphere", Los Alamos National Laboratory report LA-UR-92-2321 (1992)

8. Kantrowitz, A. (1972) Aeronaut. Astronaut. 10, 74

9. Lamberson, S., "The Airborne Laser", Proc. SPIE High Power Laser Ablation IV (2002) to appear

10. Phipps, C.R., "Dynamics of NEO Interception," Report of the NASA Near-EarthObject Interception Workshop, John D. G. Rather, Chair, Report LA-12476-C, Los Alamos National Laboratory, Los Alamos NM (1992)

11. Phipps, C.R., "Astrodynamics of Interception," in Report of the NASA Near-EarthObject Interception Workshop, John D. G. Rather, Chair (workshop summary), Report LA-12476-C, Los Alamos National Laboratory, Los Alamos, NM (1992)

12. Phipps, C.R., "Laser Deflection of NEO's," Report of the NASA Near-EarthObject Interception Workshop, John D. G. Rather, Chair, Report LA-12476-C, Los Alamos National Laboratory, Los Alamos, NM (1992)

13. Phipps, C.R., "A laser concept for clearing space junk," in AIP Conference Proceedings 318, Laser Interaction and Related Plasma Phenomena, 11th International 


\section{DRAFT}

Workshop, Monterey, CA October, 1993, George Miley, ed. American Institute of Physics, New York (1994) pp. 466-8

14. Phipps, C.R., "Lasers can play a rôle in planetary defense" in Proc. Planetary Defense Workshop, Report CONF-9505266, Lawrence Livermore National Laboratory, Livermore CA (1995)

15. Phipps, C.R., and Michaelis, M.M, "NEO-LISP: deflecting near-earth objects using high average power, repetitively pulsed lasers", Inst. Phys. Conf. Ser. 140 section 9, pp. 383-7, ICP Publishing, Bristol (1995)

16. Phipps, C.R., Friedman, H., Gavel, D., Murray, J., Albrecht, G., George, E.V., Ho, C., Priedhorsky, W., Michaelis M.M., and Reilly, J.P., "ORION: Clearing near-Earth space debris using a 20-kW, 530-nm, Earth-based, repetitively pulsed laser", Laser and Particle Beams, 14 (1996) pp. 1-44

17. Phipps, C.R., "Laser Deflection of Near-Earth Asteroids and Comet Nuclei", Proc. International Conference on Lasers 96, STS Press, McLean, VA (1997) pp. 580-7

18. Phipps, C.R., "Requirements for Laser Acquisition of NEO's", Proc. International Conference on Lasers 97, STS Press, McLean, VA (1998) pp. 928-34

19. Phipps, C.R., "Review of Direct-Drive Laser Space Propulsion Concepts", AIP

Conference Proceedings 420, Space Technology and Applications International Forum 1998, M. El-Genk, ed., American Institute of Physics, Woodbury, NY (1998) pp. 1073-80

20. Phipps, C.R., Reilly, J.P., and Campbell, J.W., "Optimum Parameters for Laserlaunching Objects into Low Earth Orbit", J. Laser and Particle Beams, 18 no. 4 pp. 661-695 (2000)

21. Phipps, C.R. and Luke, J.R., "Diode Laser-driven Microthrusters: A New

Departure for Micropropulsion", AIAA Journal, 40, no. 1, pp. 1-9 (2002)

22. Reilly, J.P., Phipps, C.R., and Campbell, J.W., "Comparison of Repetitive-pulse laser Approaches for Boosting Small Payloads into LEO," Proc. Santa Fe High Power Laser Ablation Conference III, SPIE 4065 (2000) pp. 946

23. Riker, J., "Space Based Laser Overview and Target Interactions," Proc. SPIE High Power Laser Ablation IV (2002) to appear

24. Sharpton, V.L., Nature, October 29, 1993; Sky and Telescope, July 1991, page 38; Sky and Telescope, January 1993, page 12.

25. Shoemaker, E. M. "The NEO Flux, Present and Past", Proc. Lawrence Livermore National Laboratory Planetary Defense Workshop, Report CONF-9505266, Lawrence Livermore National Laboratory, Livermore CA (1995)

26. Solem, J. C. "Nuclear Explosive Propelled Interceptor for Deflecting Comets and Asteroids on a Potentially Catastrophic Collision Course with Earth", Report of the NASA Near-Earth-Object Interception Workshop, January 14-16, 1992, Los Alamos, NM, John D. G. Rather, Chair, Los Alamos National Laboratory Report LA-12476-C (1993) 


\section{DRAFT}




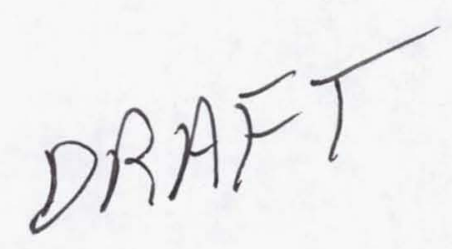

The IMPACT IMPERATIVE - Laser Ablation For Deflecting Asteroids, Meteoroids, And Comets From Impacting The Earth

\author{
J. Campbell \\ NASA/MSFC \\ C. Phipps \\ L. Smalley \\ University of Alabama, Huntsville \\ J. Reilly \\ D. Boccio \\ Queensborough Community College of the \\ City University of New York
}




\section{Comet P/Shoemaker-Levy 9 (1993e)}

"String of Pearls"

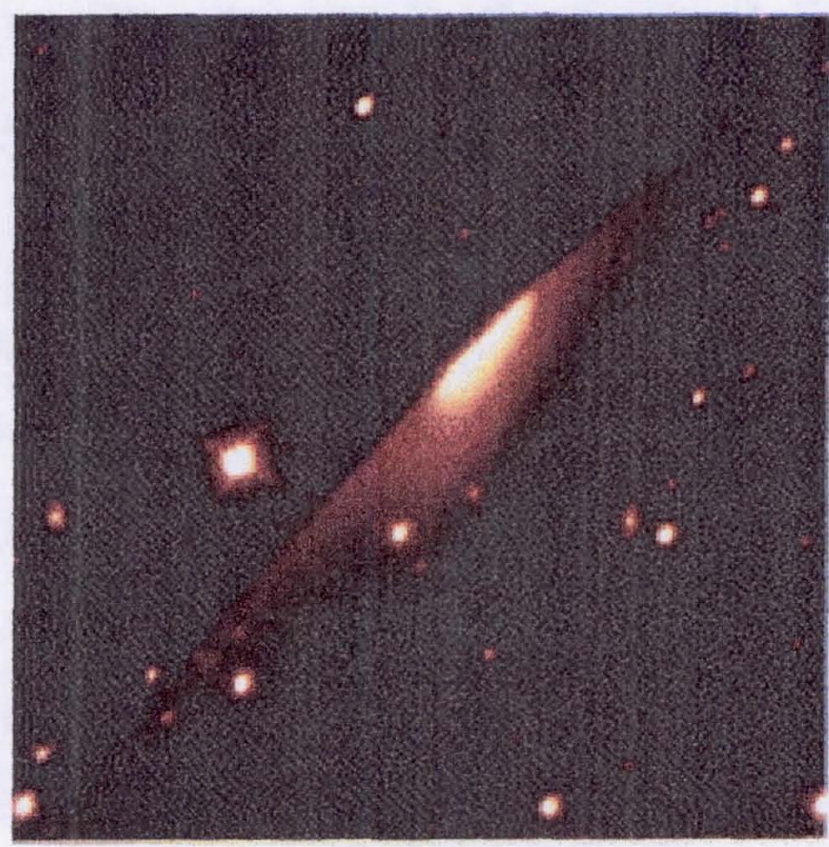

600000 MILES

Ground Based

Wide Angle View

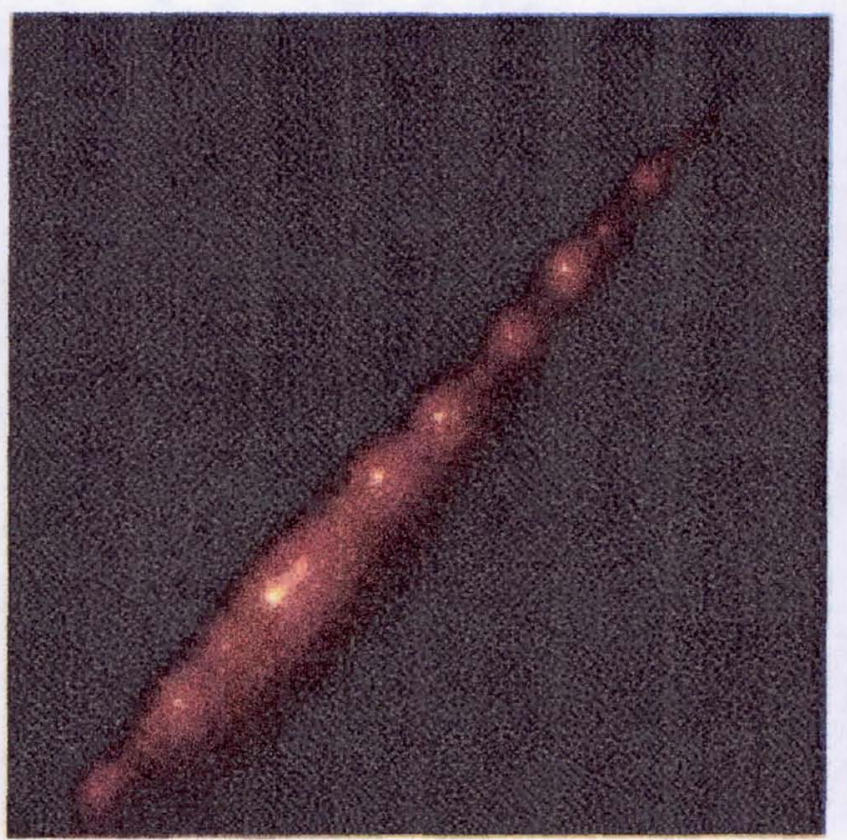

100,000 MILES

HST View

Region Containing the Nuclet

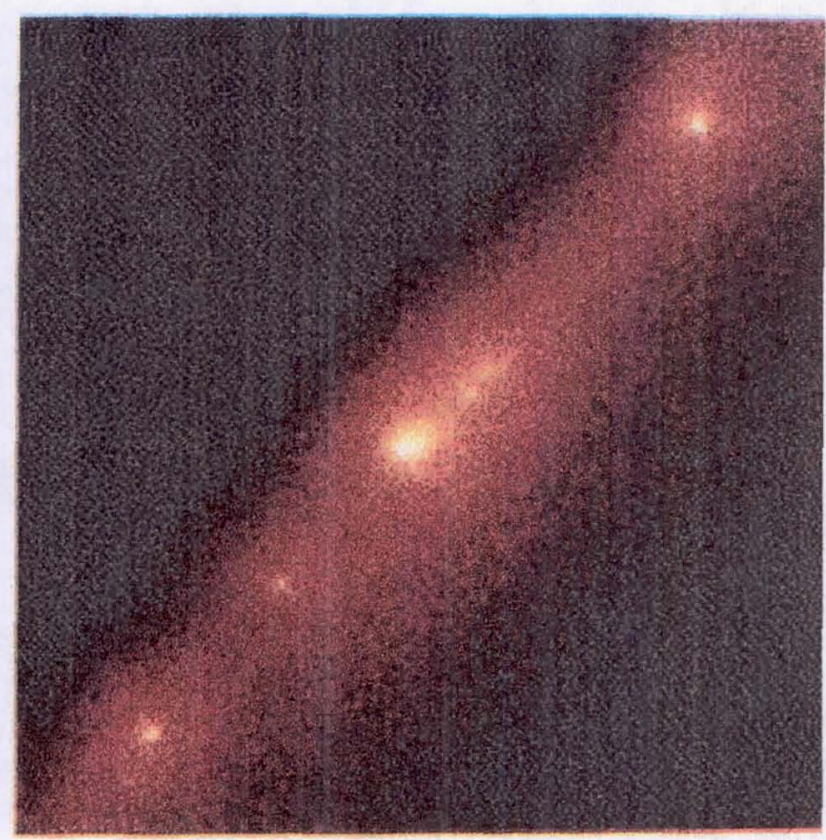

40,000 MHLES HST View

Closeup Near Brightest Nucleus 
The Comet

Approaching Jupiter

Note the apparent linear alignment of multiple objects 


\section{Linear Impact} Sites on Jupiter

1. 151 国?

H

DEIII

ElE 


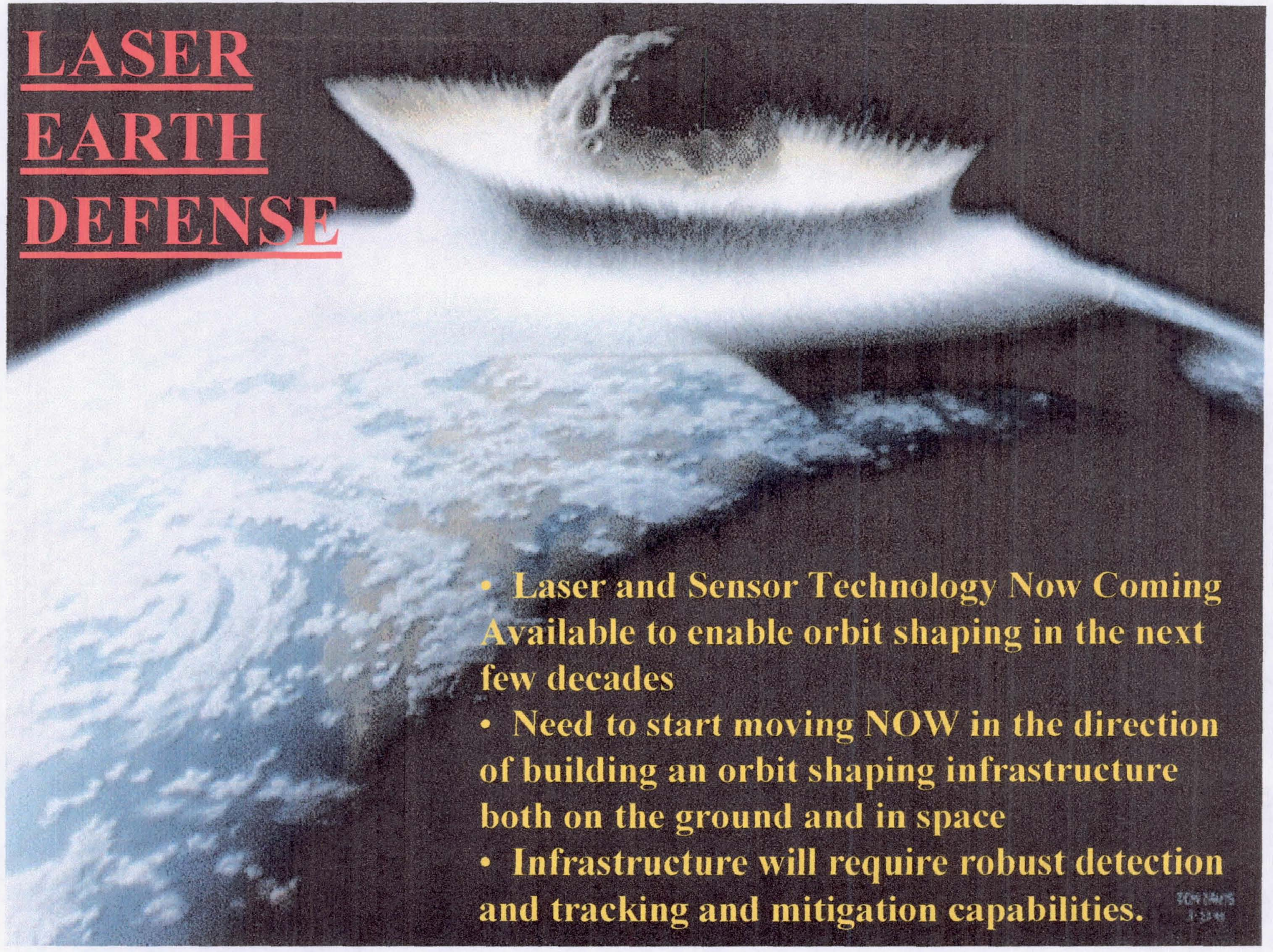




\section{Asteroid Population}

- Estimated 200,000 $100 \mathrm{~m}$ class objects in orbits crossing the Earth's

- Estimated 2000 1-10 km class objects

- $>10 \mathrm{~km}$ TBD

- numbers do not include comets

- Many asteroids not yet detected and orbits not yet known

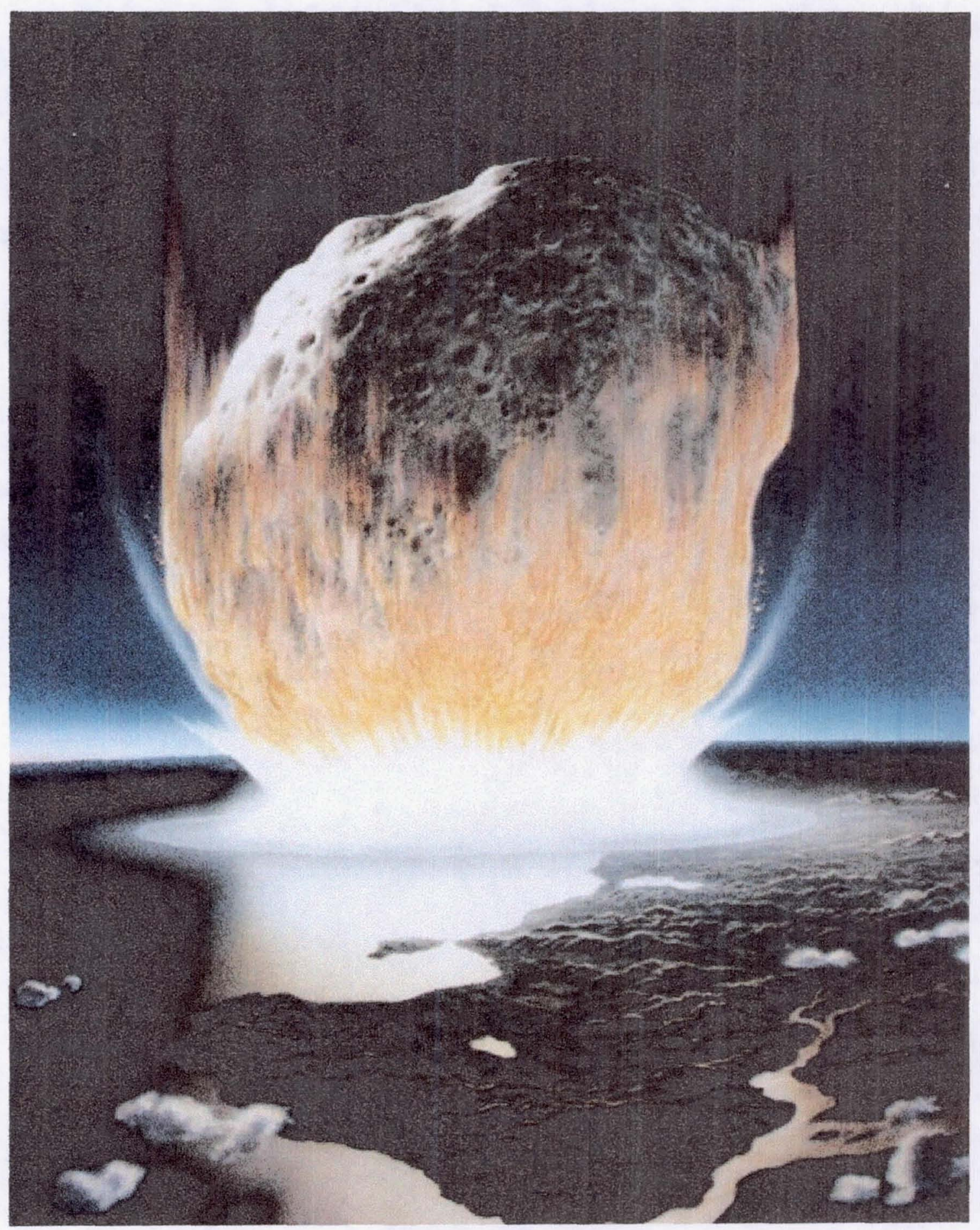


Kinetic Energy (Megatons) of NEO vs. Diameter for various densities and relative velocities

Kinetic energy (MT) vs diameter of Earth-crossing asteroids (NEO's) with velocity 10 to $30 \mathrm{~km} / \mathrm{s}$ and density $\rho=1000-9000 \mathrm{~kg} / \mathrm{m} 3$. Below the chart, total number of NEO's and probability of Earth impact are shown. A $100 \mathrm{~m}$ class object impacting the Earth releases on the order of 10 MT of energy.

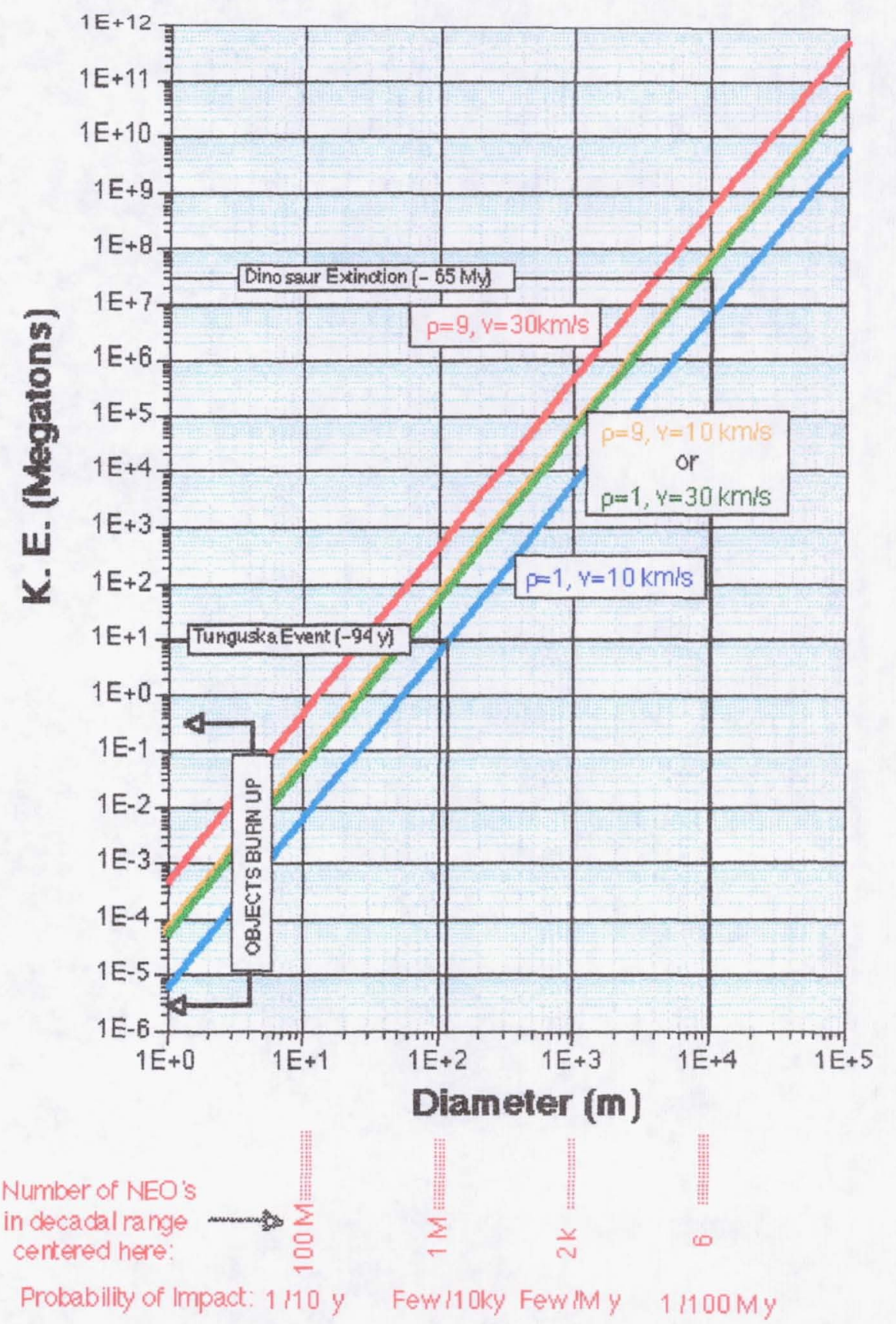




\section{Near-Earth Asteroids (NEO's)}

- Classified as Potentially Hazardous

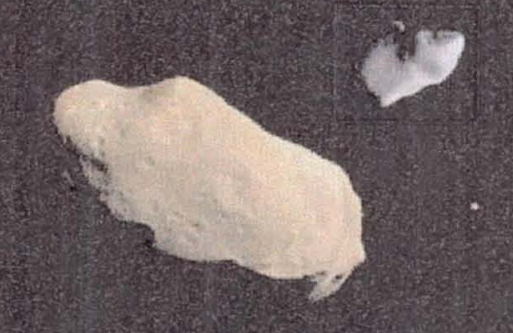

- Have Earth-Crossing Orbits

- Hypervelocity's mean small sizes impacting cause great disasters

- Over 200,000 Estimated 100 m class objects

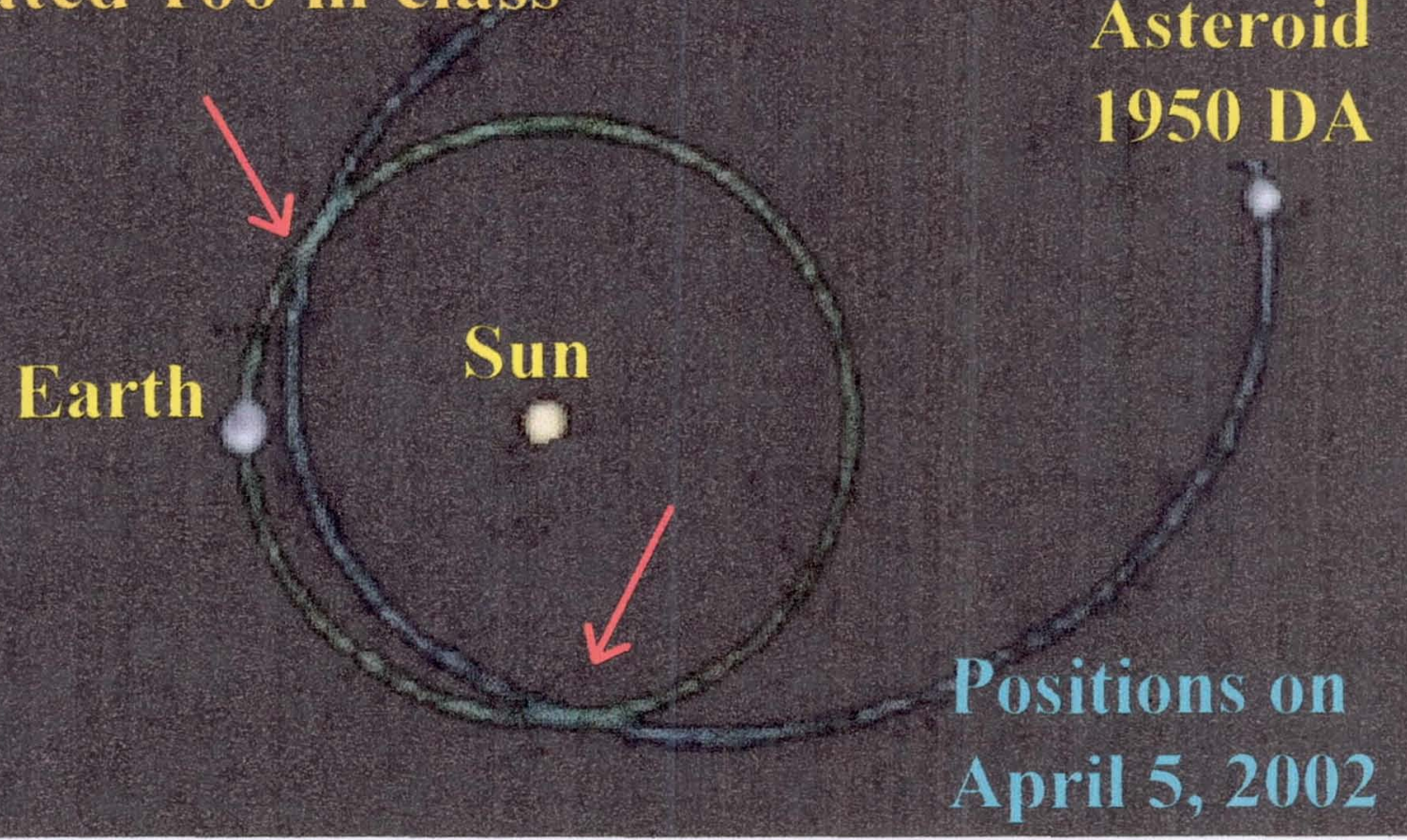




\section{Near-Miss Asteroids}

- Pass within $1 \mathrm{AU}\left(1.5 \times 10^{8}\right.$ km)

- Over 1700 recorded

- Normally not a factor unless perturbed

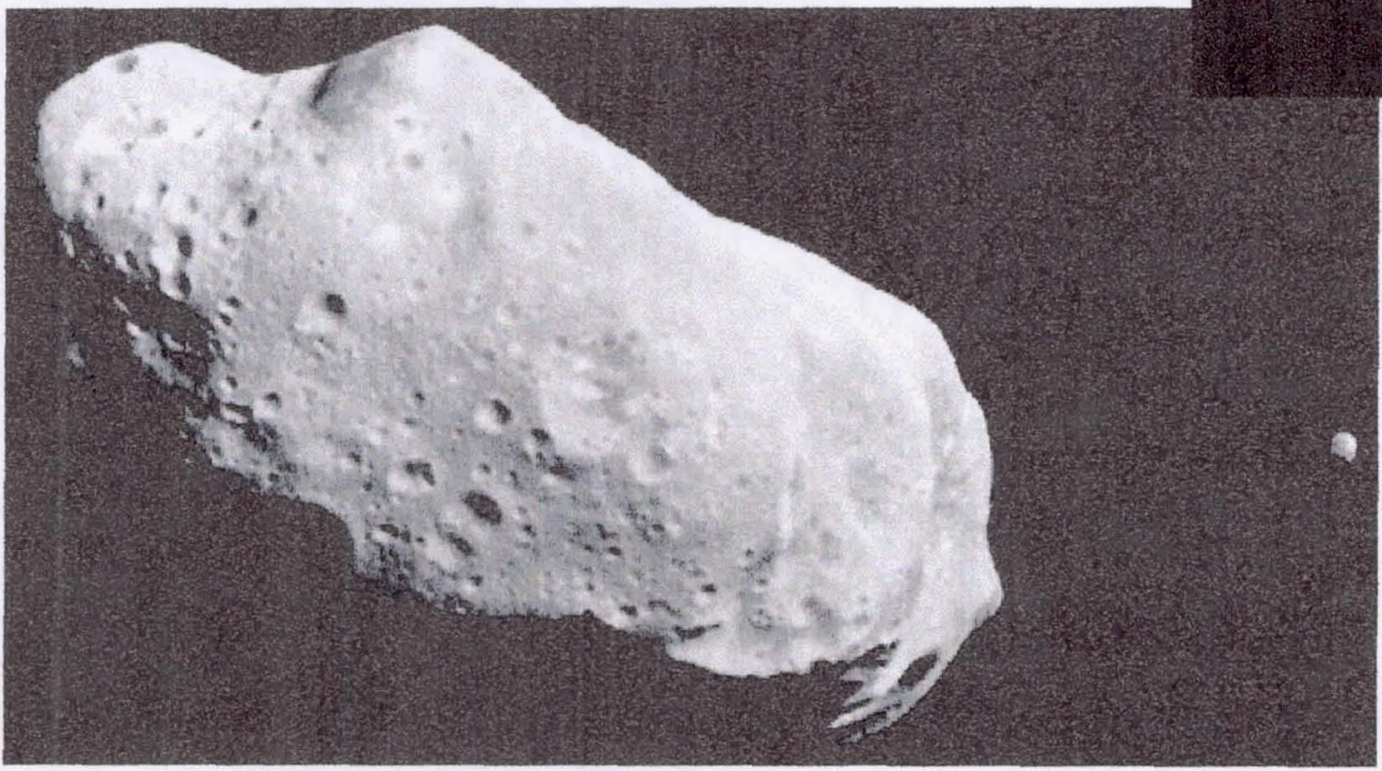

- Results of summer study indicate that a smaller object impacting a larger rock may force it from its stable, "safe" orbit into an impact orbit with the Earth 


\section{Destabilizing Event Simulation}

- A small meteoroid may collide into large asteroid in a stable safe orbit

- Causes orbit to become unstable

- Simulation Sequence

- House-size rock hits asteroid $(3 / 4-\mathrm{km}$ diameter)

- Transfers momentum

- Alters orbit sufficiently to become potentially dangerous

to Earth

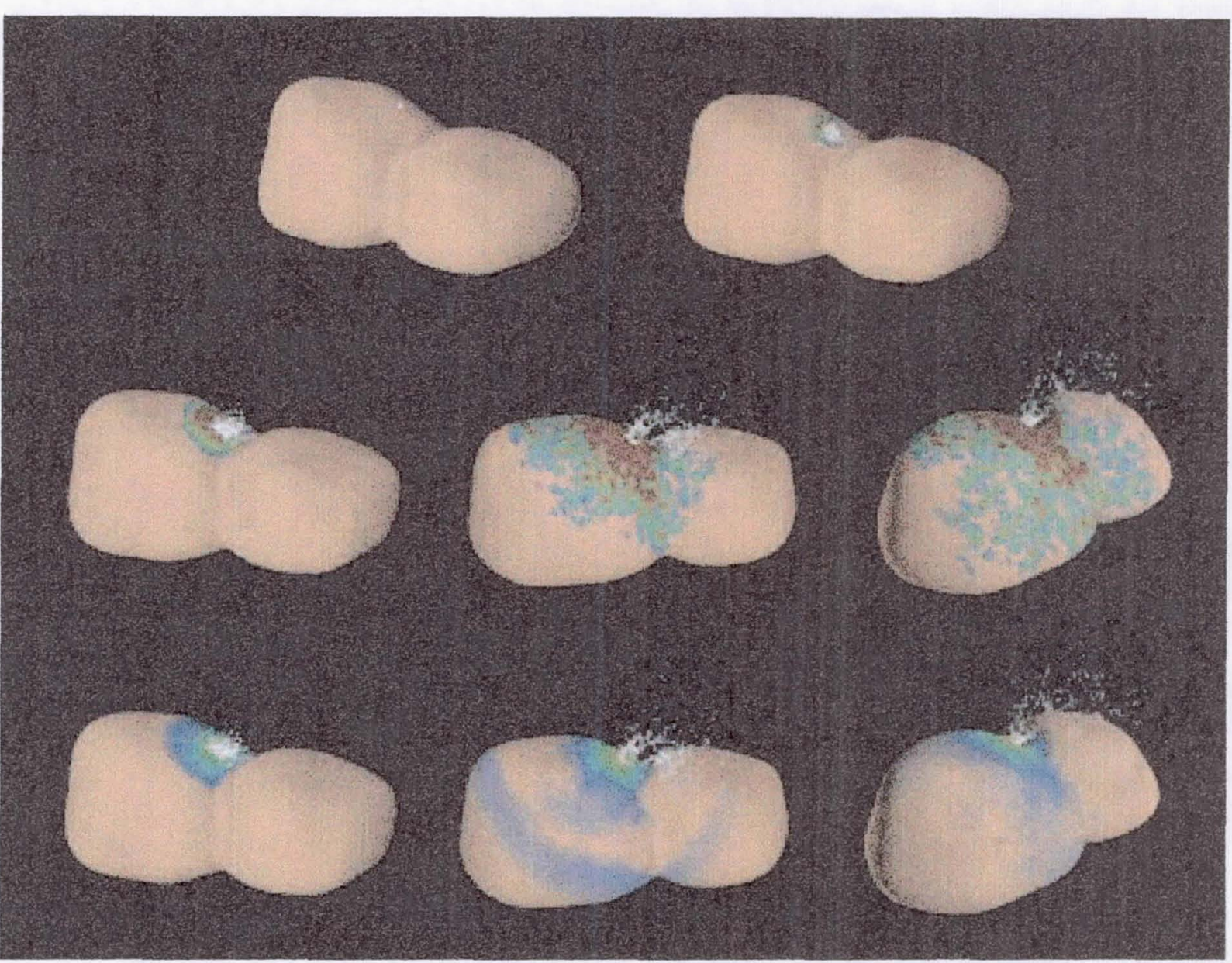




\section{IMPACT DAMAGE MECHANISMS}

* Crater formation

\section{SHORT TERM}

\section{LONG TERM}

* Sun-obscuring dust and clouds

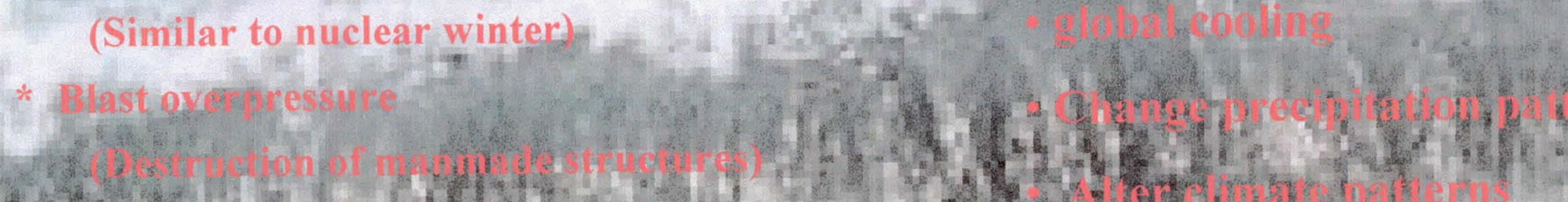

- Block out Sun's rays

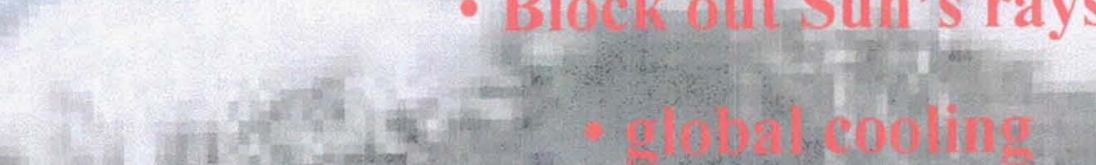

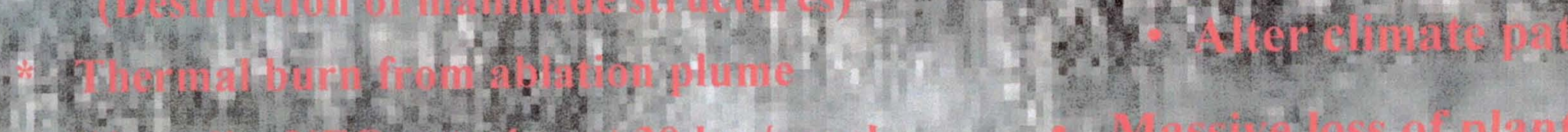

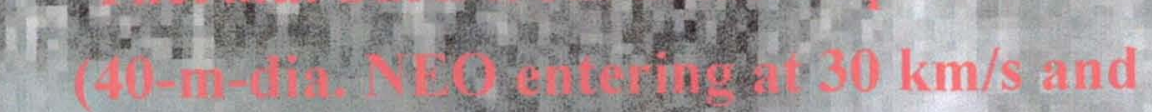

10 kint

Hills

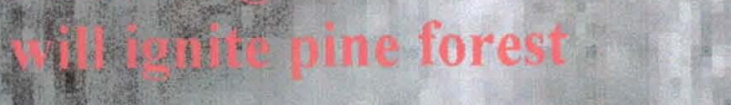
(6)

* Earthquakes

(A $30 \mathrm{~km} / \mathrm{s}, 80$-m-dia. iron NEO will cause a Richter 7 quake [Hills 1992])

* Ram-up of deep water tsunami

(Tsunami from a $30 \mathrm{~km} / \mathrm{s}, 80$-m-dia. Iron NEO will cause a 40 -m-high tidal wave

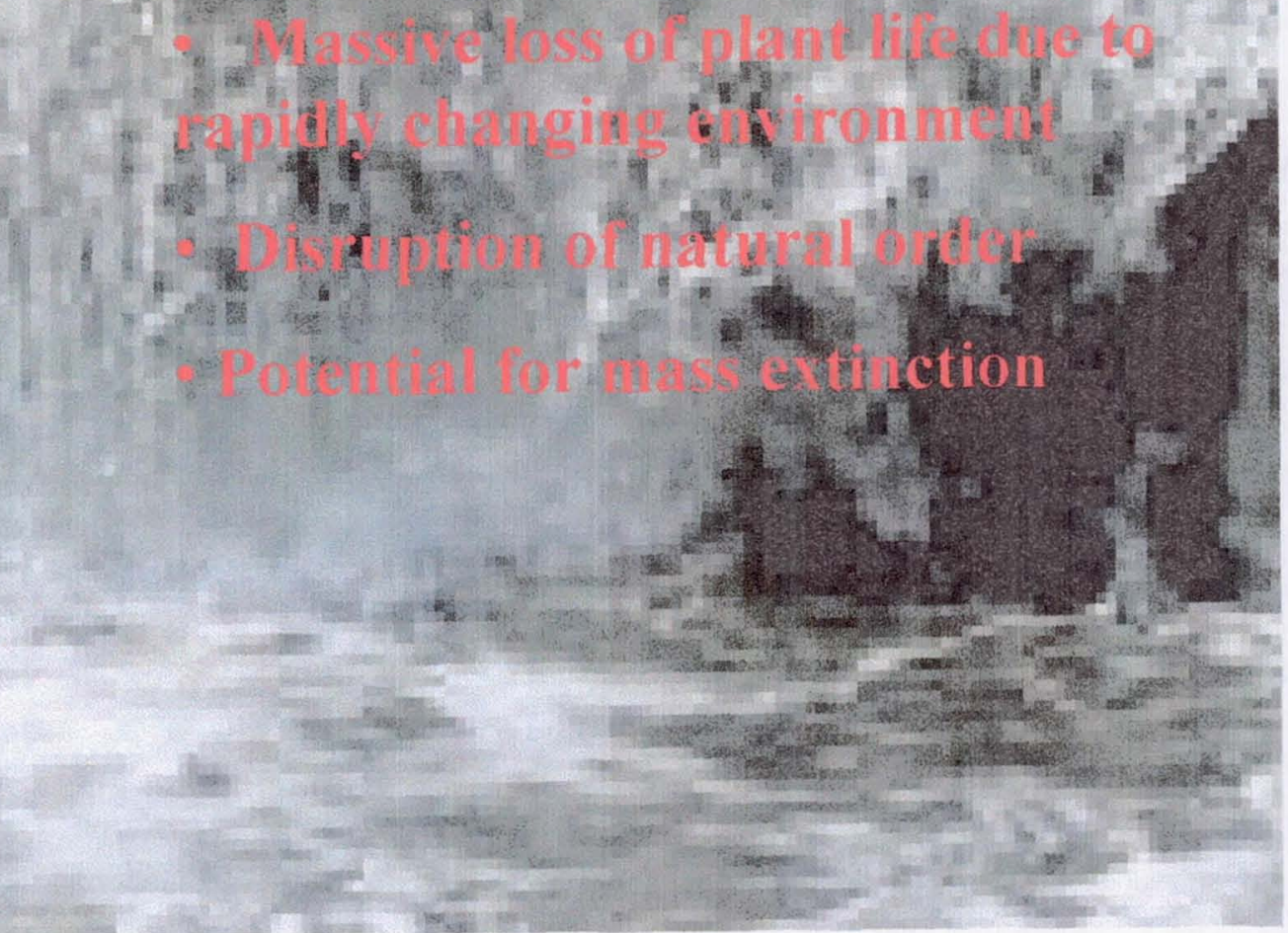




\section{The Asteroid Impact Site}

On The Yucatan Peninsula Is Only Visible Using Space-based Sensors
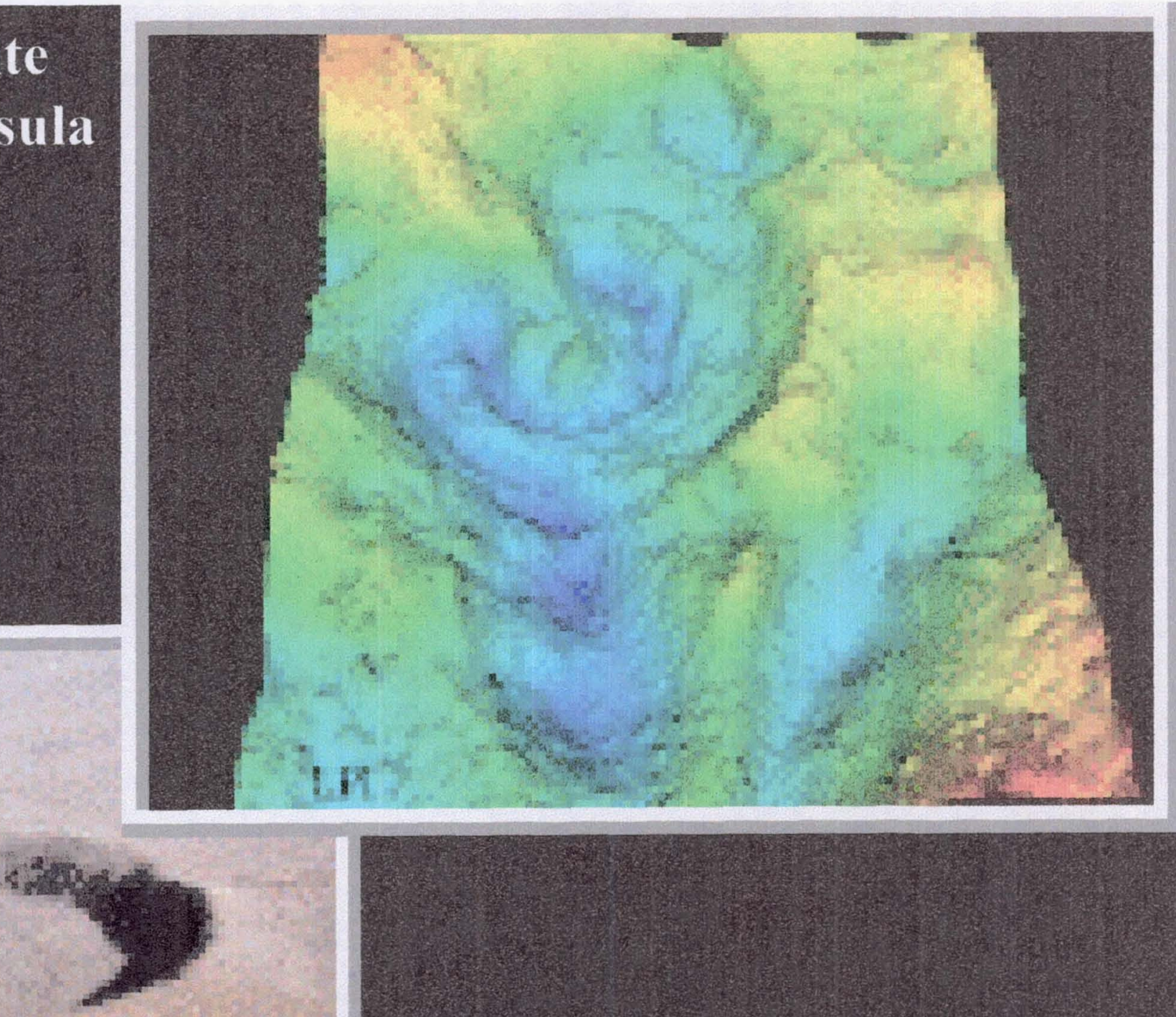

The Earth Has Been Struck Many Times In The Past. This is a Crater Found in Australia. 


\section{Tunguska in Siberia, Russia}

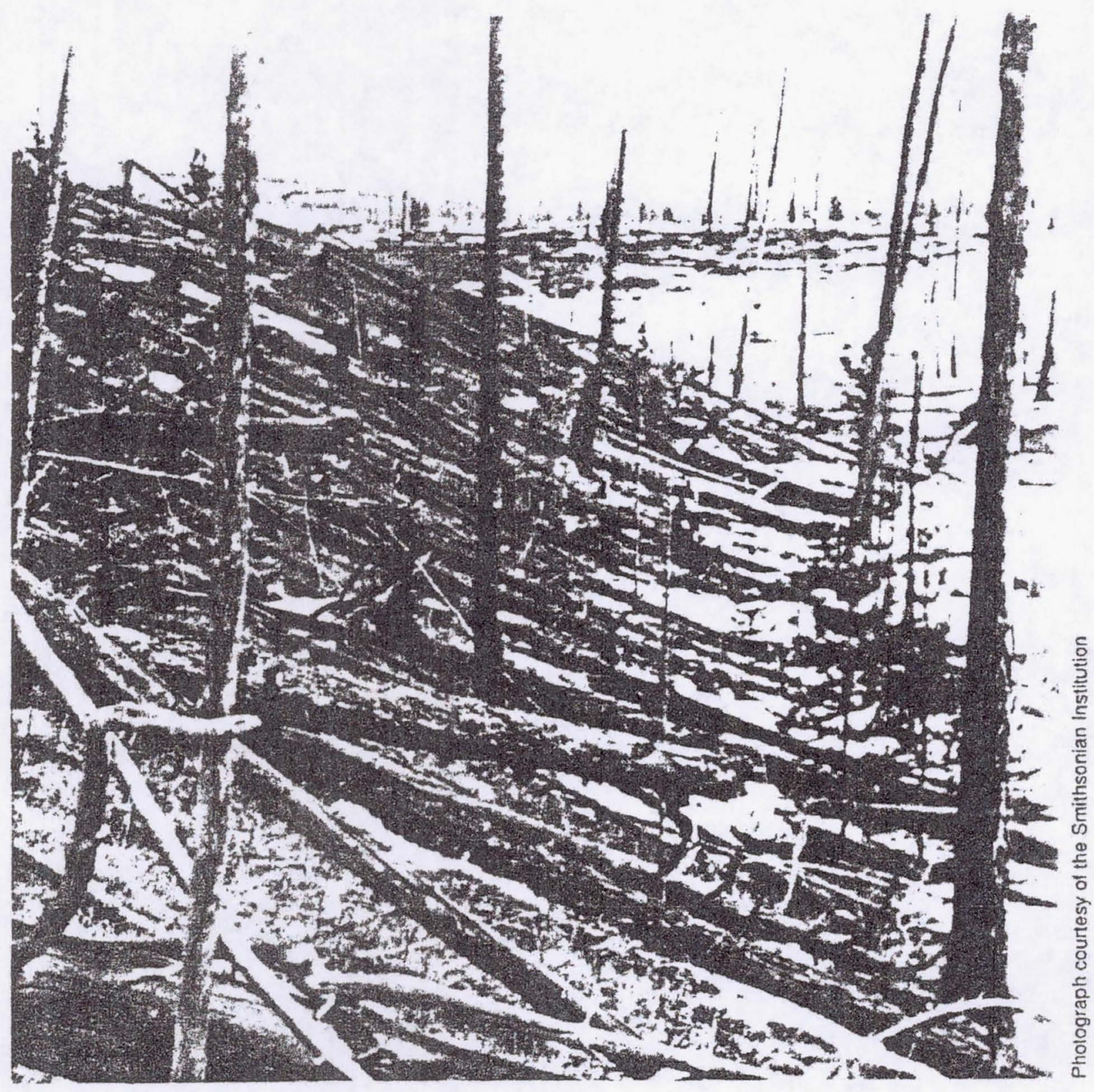

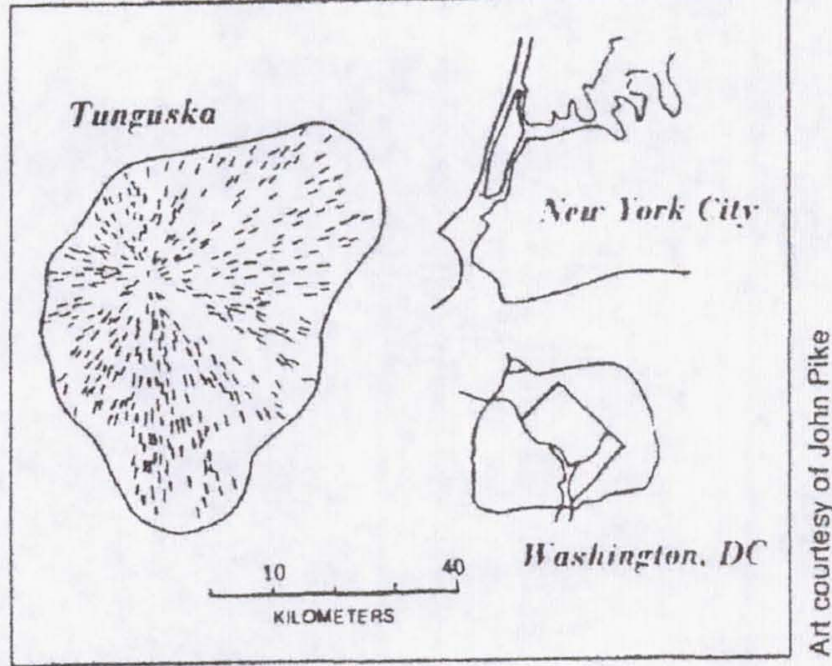

Tunguska in perspective

- About 100 m diameter

- Asteroid exploded above ground

- Energy release on the order of 10 MT

- Destruction of nearly 500,000 acres of trees

On eJune 30, 1908, at 7:40 AM, a cosmic projectile exploded in the sky over Siberia. It flattened 2,000 square kilometers of forest in the Tunguska region. If a similar event were to occur over an urban area today, hundreds of thousands of people would be killed, and damage would be measured in hundreds of billions of dollars. 


\section{Mass Extinctions}

\begin{tabular}{|c|l|}
\hline $\begin{array}{c}\text { Time } \\
\text { years ago }\end{array}$ & $\begin{array}{l}\text { Geological Period } \\
\text { Ordovician/Silurian } \\
\text { boundary }\end{array}$ \\
\hline $\begin{array}{c}\text { years ago } \\
\text { yen million }\end{array}$ & $\begin{array}{l}\text { Devonian/Carboniferous } \\
\text { boundary }\end{array}$ \\
\hline years ago & $\begin{array}{l}\text { Permian/Triassic } \\
\text { boundary }\end{array}$ \\
\hline $\begin{array}{c}\text { 208 million } \\
\text { years ago }\end{array}$ & $\begin{array}{l}\text { Triassic/Jurassic } \\
\text { boundary }\end{array}$ \\
\hline $\begin{array}{c}\text { 65 million } \\
\text { years ago }\end{array}$ & $\begin{array}{l}\text { Cretaceous/Tertiary } \\
\text { boundary }(\mathbf{K} / \mathbf{T})\end{array}$ \\
\hline
\end{tabular}

- 5 major mass extinctions

- High probability impact event associated cause in $1^{\text {st }}$ and last (dinosaurs)

- Impact event strongly suspected in other three

-Effects: volcanism, earthquakes changes in ocean oxygen, sea level, and climate, mass extinction

- $95 \%$ all species in $\mathbf{1}^{\text {st }}, 70 \%$ all species in last 


\section{THE TORINO SCALE Assessing Asteroid and Comet Impact Hazard Predictions in the 21 st Century}

\begin{tabular}{|c|c|c|}
\hline \multirow{3}{*}{$\begin{array}{c}\text { Events Having } \\
\text { No Likely } \\
\text { Consequences } \\
\text { Evgnts } \\
\text { Merling Careful } \\
\text { Monltoring }\end{array}$} & & $\begin{array}{l}\text { The likelihood of a collision is zero, or well below } \\
\text { the chance that a random object of the same size } \\
\text { will strike the Earth within the next few decades. } \\
\text { This designation also applies to any small object } \\
\text { that, in the event of a collision, is unlikely } \\
\text { to reach the Earth's surface intact. }\end{array}$ \\
\hline & & $\begin{array}{l}\text { The chance of collision is extremely unlikely, about } \\
\text { the same as a random object of the same size } \\
\text { striking the Earth within the next few decades. }\end{array}$ \\
\hline & & $\begin{array}{l}\text { A somewhat close, but not unusual encounter. } \\
\text { Collision is very unlikely. }\end{array}$ \\
\hline \multirow{3}{*}{ 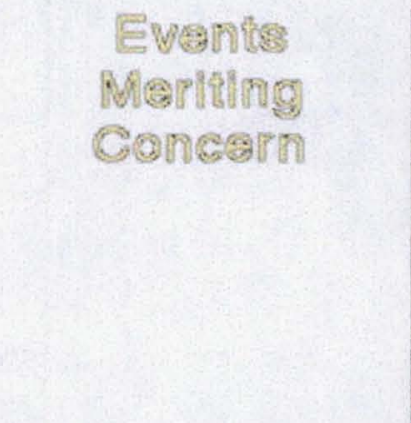 } & & $\begin{array}{l}\text { A close encounter, with } 1 \% \text { or greater chance of a } \\
\text { collision capable of causing localized destruction. }\end{array}$ \\
\hline & & $\begin{array}{l}\text { A close encounter, with } 1 \% \text { or greater chance of a } \\
\text { collision capable of causing regional devastation. }\end{array}$ \\
\hline & & $\begin{array}{l}\text { A close encounter, with a significant threat of a } \\
\text { collision capable of causing regional devastation. }\end{array}$ \\
\hline \multirow[t]{3}{*}{$\begin{array}{c}\text { Throatening } \\
\text { Events }\end{array}$} & & $\begin{array}{l}\text { A close encounter, with a significant threat of a } \\
\text { collision capable of causing a global catastrophe. }\end{array}$ \\
\hline & & $\begin{array}{l}\text { A close encounter, with an extremely significant threat } \\
\text { of a collision capable of causing a global catastrophe }\end{array}$ \\
\hline & & $\begin{array}{l}\text { A collision capable of causing localized destruction } \\
\text { Such events occur somewhere on Earth between } \\
\text { once per } 50 \text { years and once per } 1000 \text { years. }\end{array}$ \\
\hline \multirow[t]{2}{*}{$\begin{array}{l}\text { Corialn } \\
\text { Collialons }\end{array}$} & & $\begin{array}{l}\text { A collision capable of causing regional devastation. } \\
\text { Such events occur between once per } 1000 \text { years } \\
\text { and once per } 100,000 \text { years. }\end{array}$ \\
\hline & & $\begin{array}{l}\text { A collision capable of causing a global climatic } \\
\text { catastrophe. Such events occur once per } \\
100.000 \text { years, or less often. }\end{array}$ \\
\hline
\end{tabular}

- Compares the magnitudes of asteroids

- Provides communication for scientists and public

- Scale ranges from 0 to 10

- Ranked based on impact probability, size, energy, and speed

- Tunguska impact would have been an 8

- 2002 NT7 is a 1 


\section{CLOSE APPROACH}

EXAMPLE I: 2002 EM77

\section{March 8, 2002}

- Was not noticed until 4 days outbound illustrates current inadequate level of Earth's early warning capability

- No response time for intervention - an impact would have caught the Earth entirely by surprise without time for evacuation or other casualty/damage minimization

- Only 1.2 times the distance to the moon $(450,000 \mathrm{~km})-$-a close call!

- Between 50-100 meters across

- Among the 10 closest known asteroids

- Has potential to collide with Earth within the next century

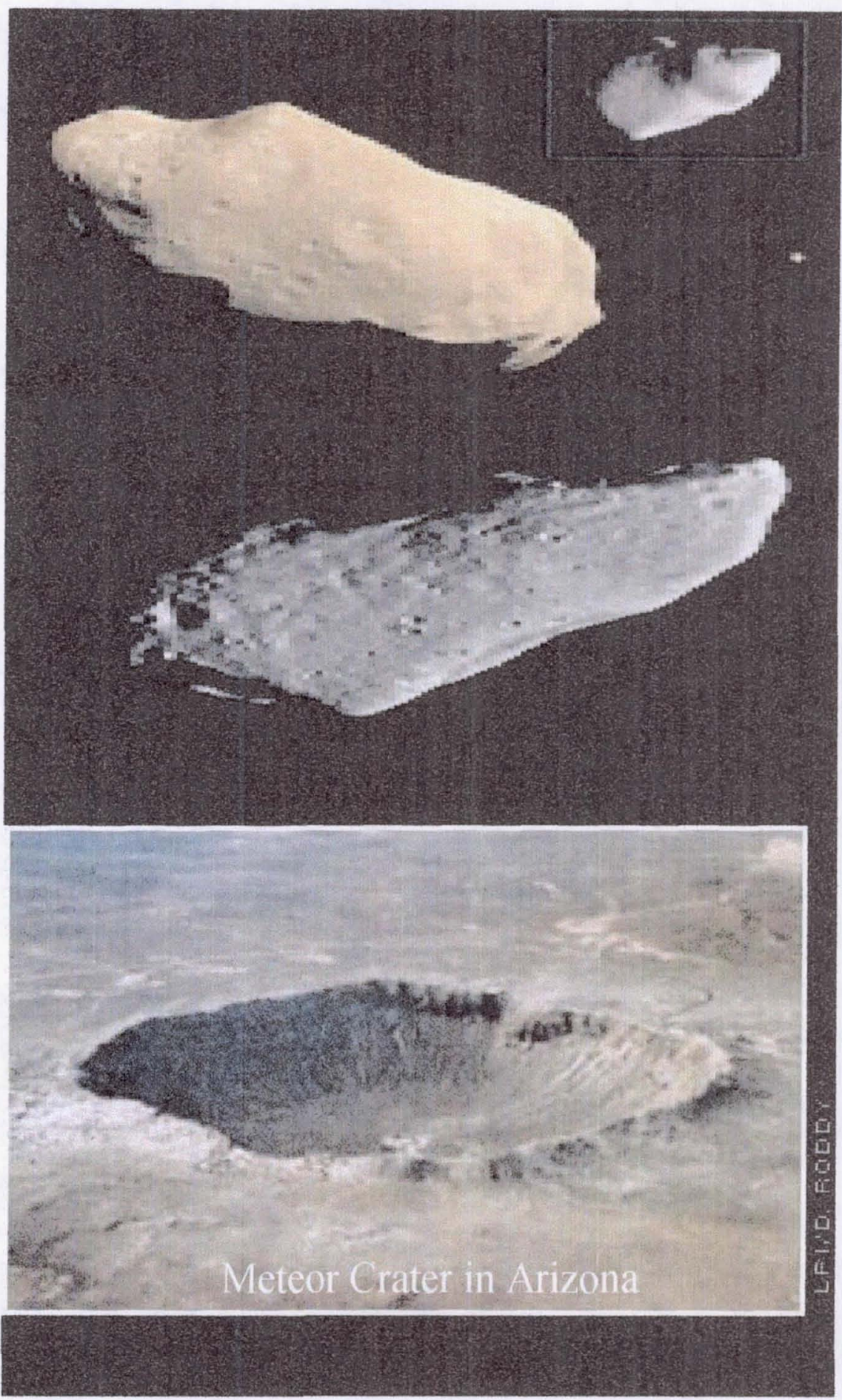




\section{CLOSE APPROACH EXAMPLE II: $2002 \mathrm{MN}$}

June 15, 2002

- Detected 2 days outbound from Earth

- Point of closest approach was 0.3 lunar distances away (within the Moon's orbit)

- Diameter was between 50-120 meters

- Nothing this close since December 1994 
CLOSE APPROACH Example III

- Asteroid 2002 NT7

- Predicted closest approach to the Earth Feb. 1, 2019

- $1.2 \mathrm{~km}$ in diameter (global disaster)

- Possible impact risk

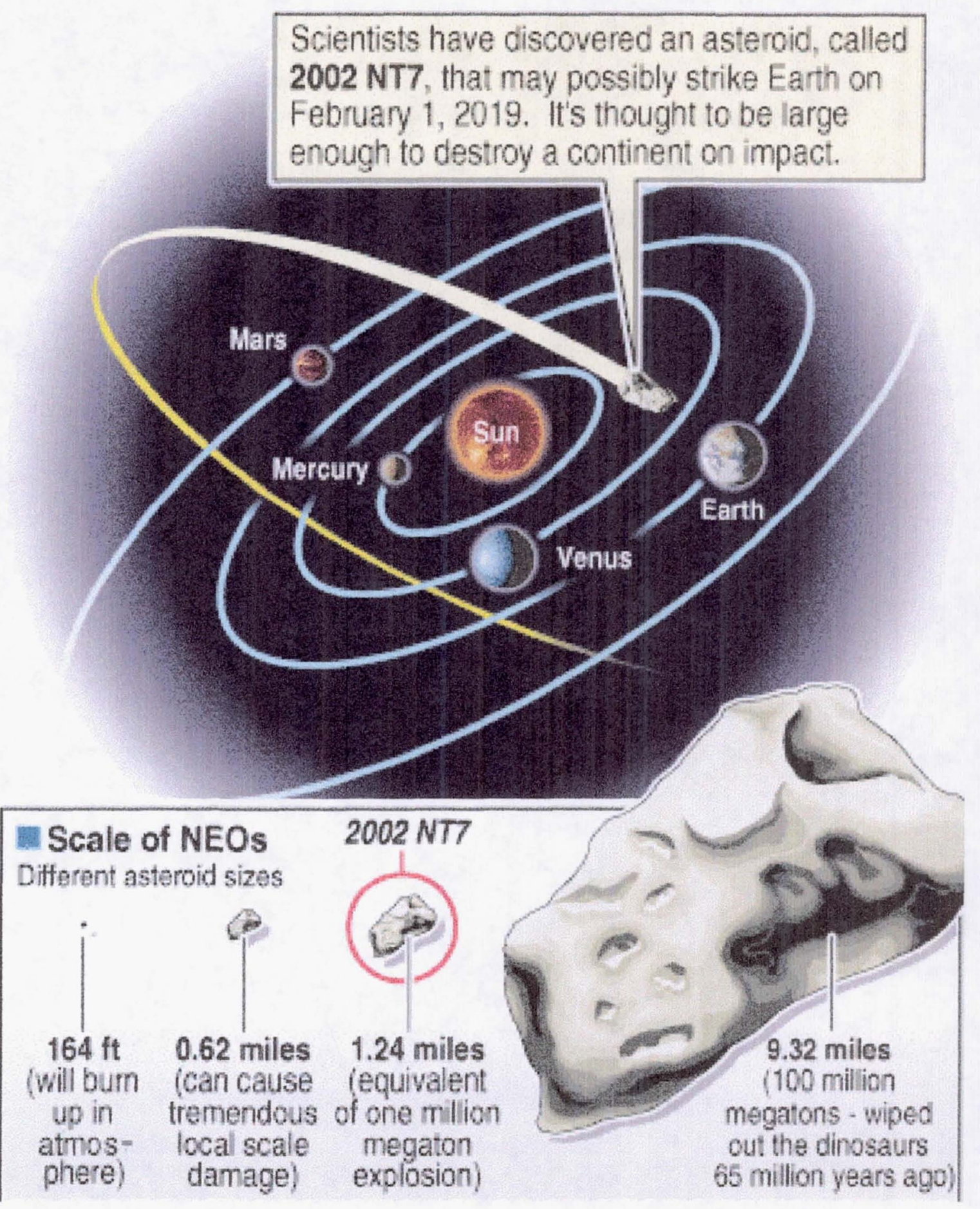




\section{Potential Impacts...What Can We Do?}

- 1 in 250,000 chance in $2019(\sim 1.2 \mathrm{~km})$

$\cdot 1$ in 300 chance in $2880(\sim 1 \mathrm{~km})$

$>$ Alert the science community and the decision makers. Define the threat. Increase awareness.

$>$ Advocate this area as a worldwide priority for international space funding

$>$ Immediately begin an international program to build an infrastructure of sensors, lasers, and other mitigative measures to accomplish orbit shaping

$>$ Objective: Conduct first orbit shaping tests on $100 \mathrm{~m}$ class object in less than 10 years 

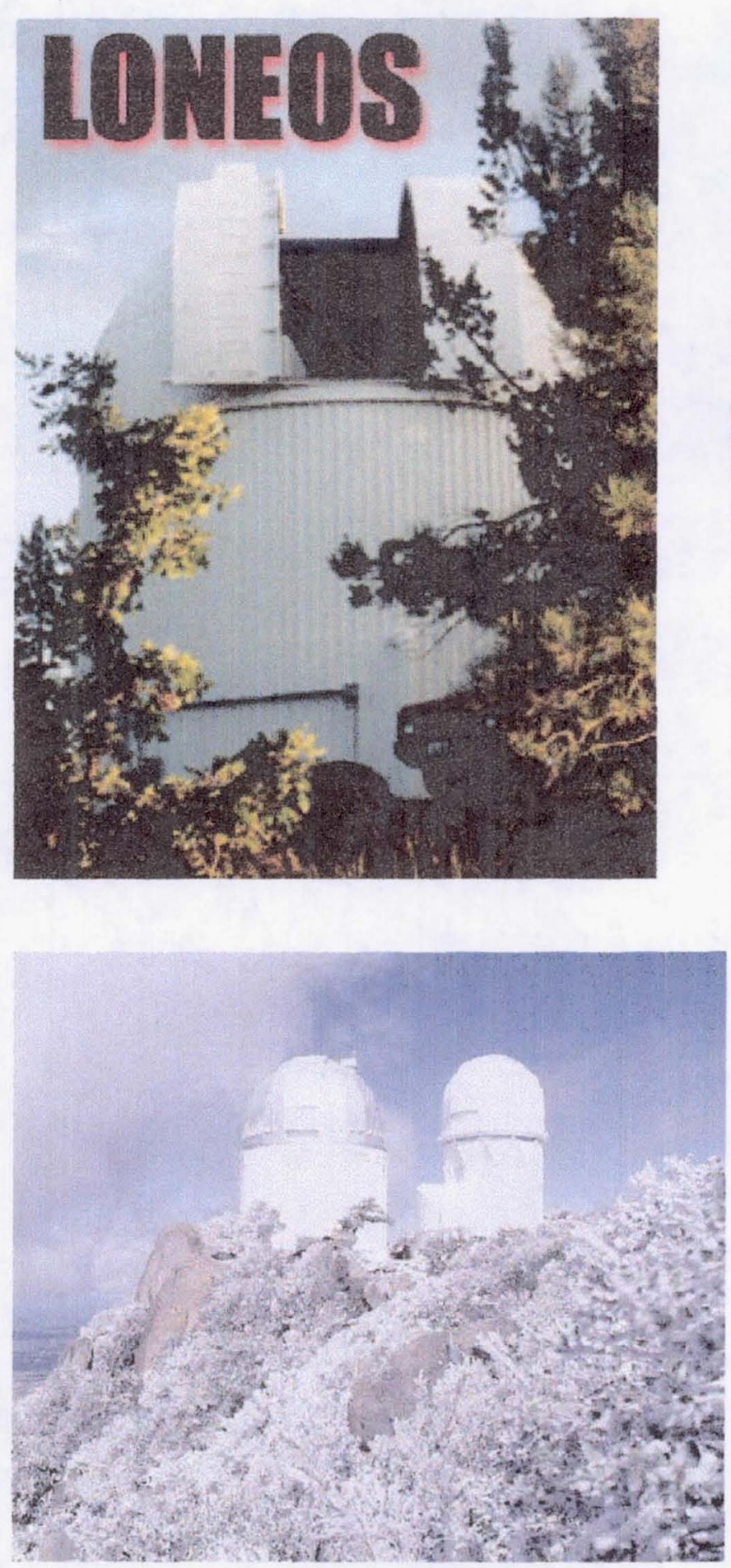
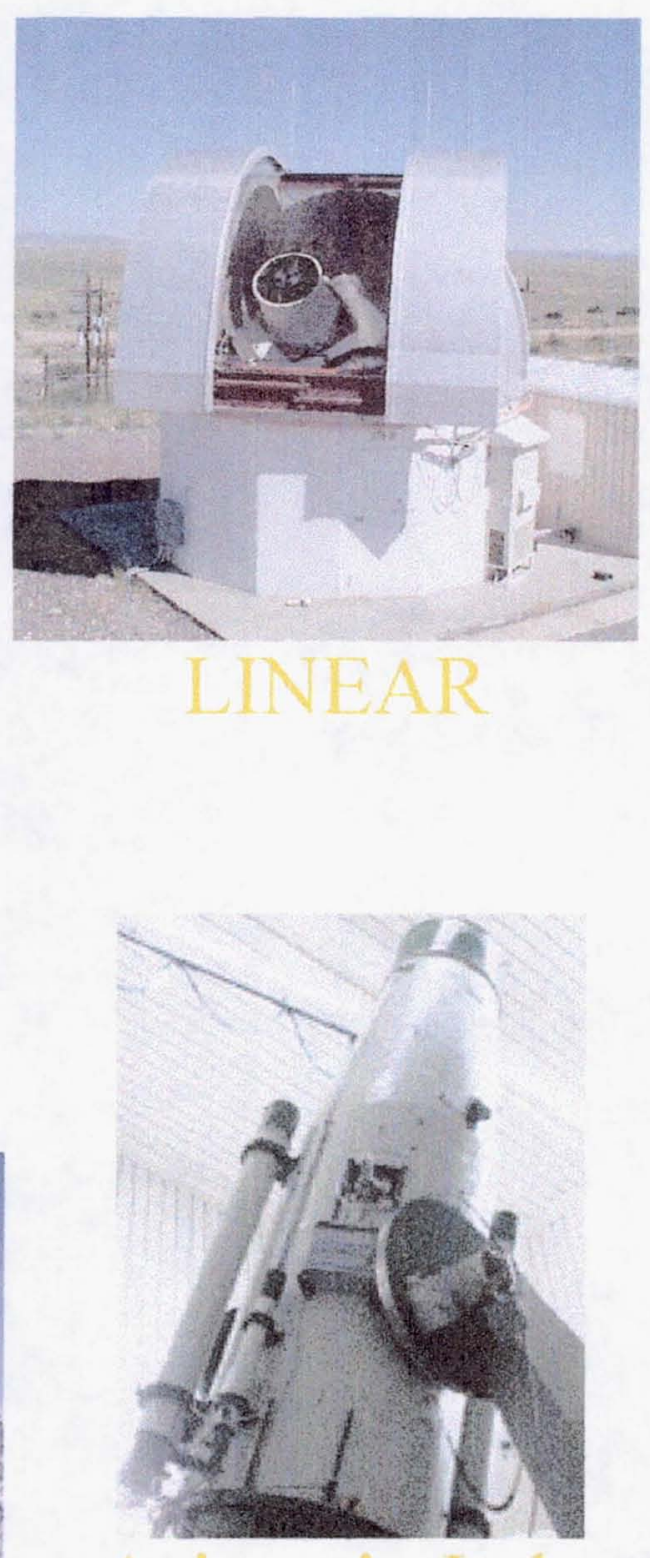

Asiago in ltaly

ASTEROID SEARCH PROGRAMS 


\section{Current Asteroid Detection}

\section{Hungarian Asteroid J95Y25R}

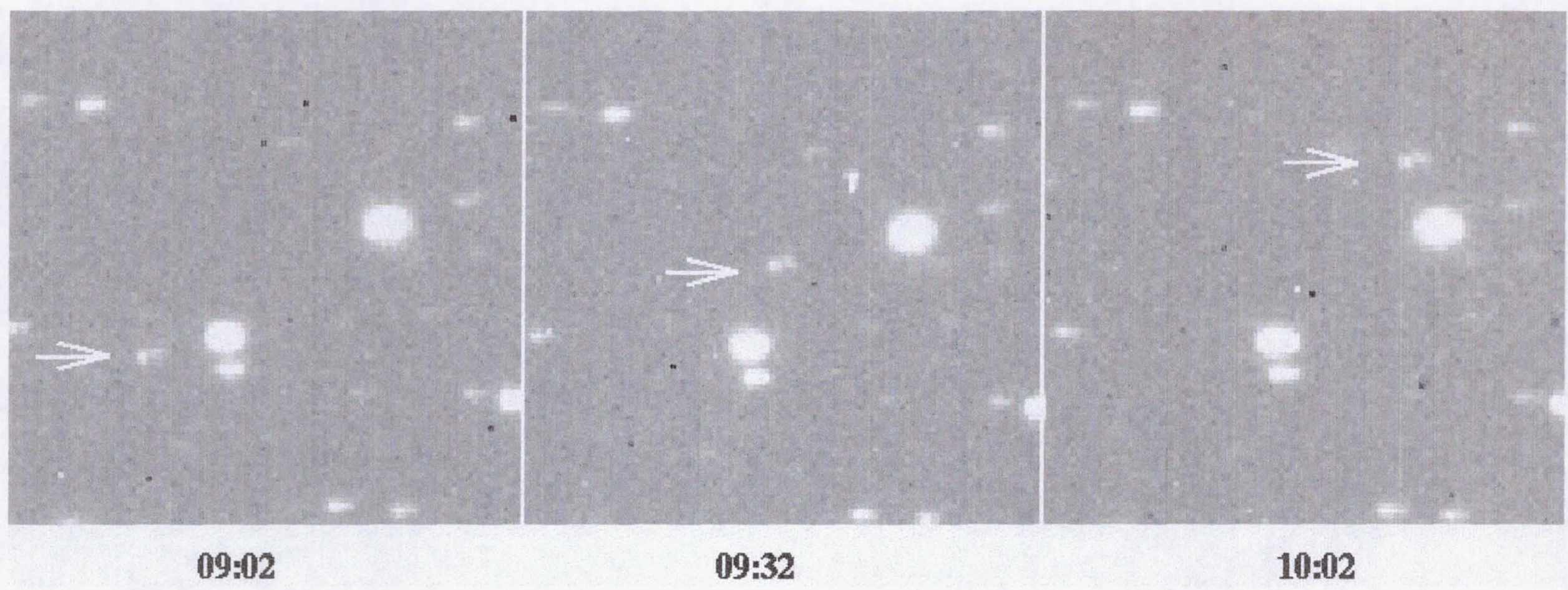

- Sky scanned nightly

- Compare for changes

- Track and check for danger

- Illustrates the difficulty in searching the entire sky to find potentially dangerous asteroids 


\section{Current Asteroid Detection Requirements}

$>$ Important Parameters:

- Size

- Brightness

- Shape and internal structure

- Surface geology

- Chemical composition

- Spin state

- Pole Orientation

$>$ Knowing these parameter crucial to calculating orbits and then planning protective measures if necessary 


\section{Advanced Detection}

- National Optical

Astronomy Observatories

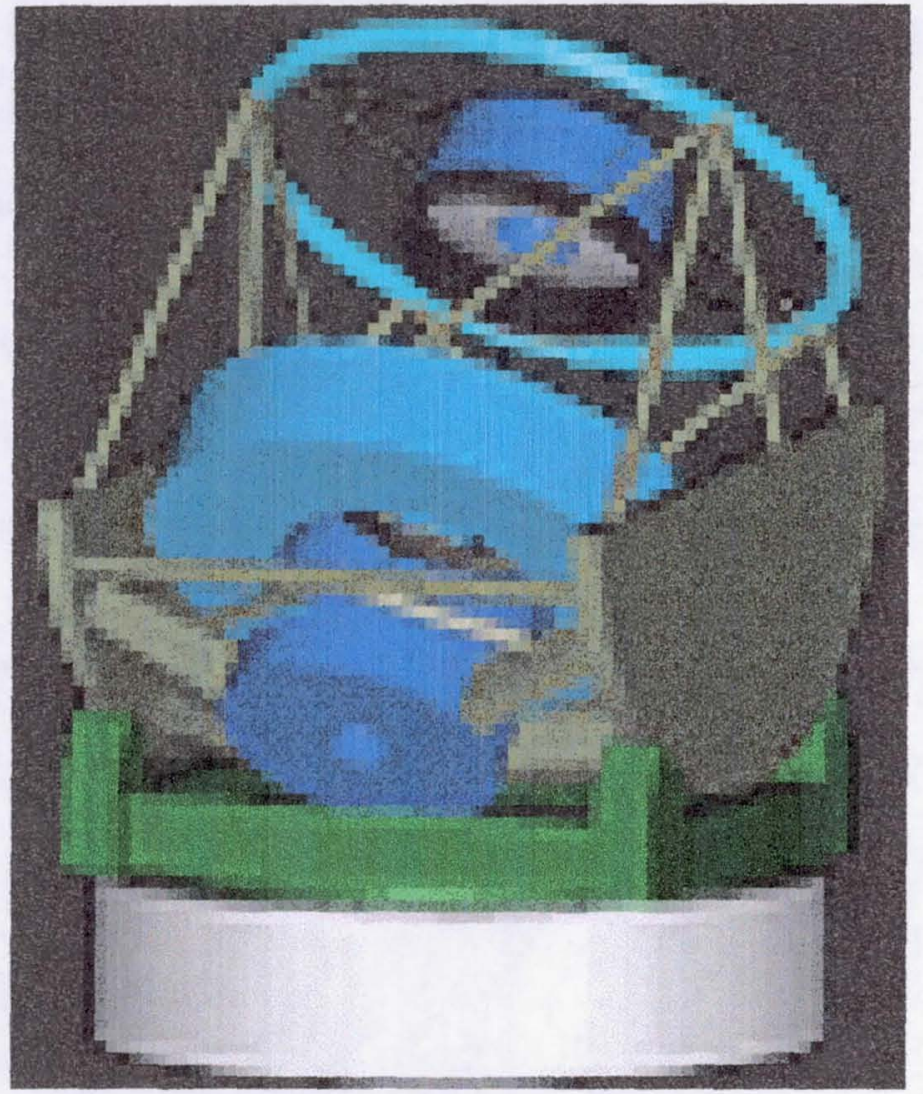

6.5-meter optical Large-Aperture

Synoptic Survey (LSST)

Telescope

- Goal: discover $90 \%$ of all 300 -meter or bigger asteroids within 10 years

-Weekly scanning

- Detect lower light levels

- \$170 million

LSST

- Multiple uses

- Advanced technologies are coming to improve Earth's detection/early warning capabilities 


\section{Laser Technology Has Turned}

The Corner And We Will See Its Increasing

Use In The Next Millenium

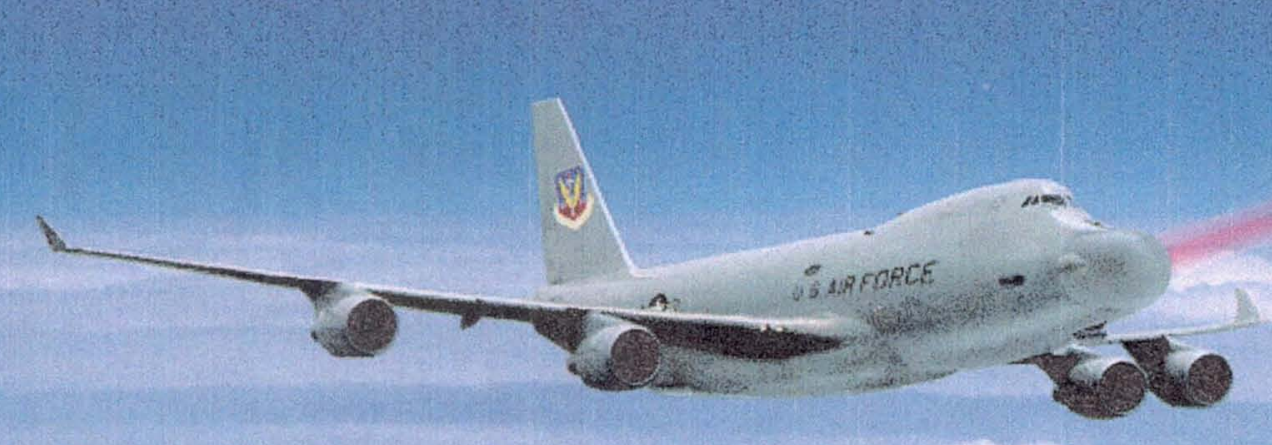




\section{EARTH Defense}

ro

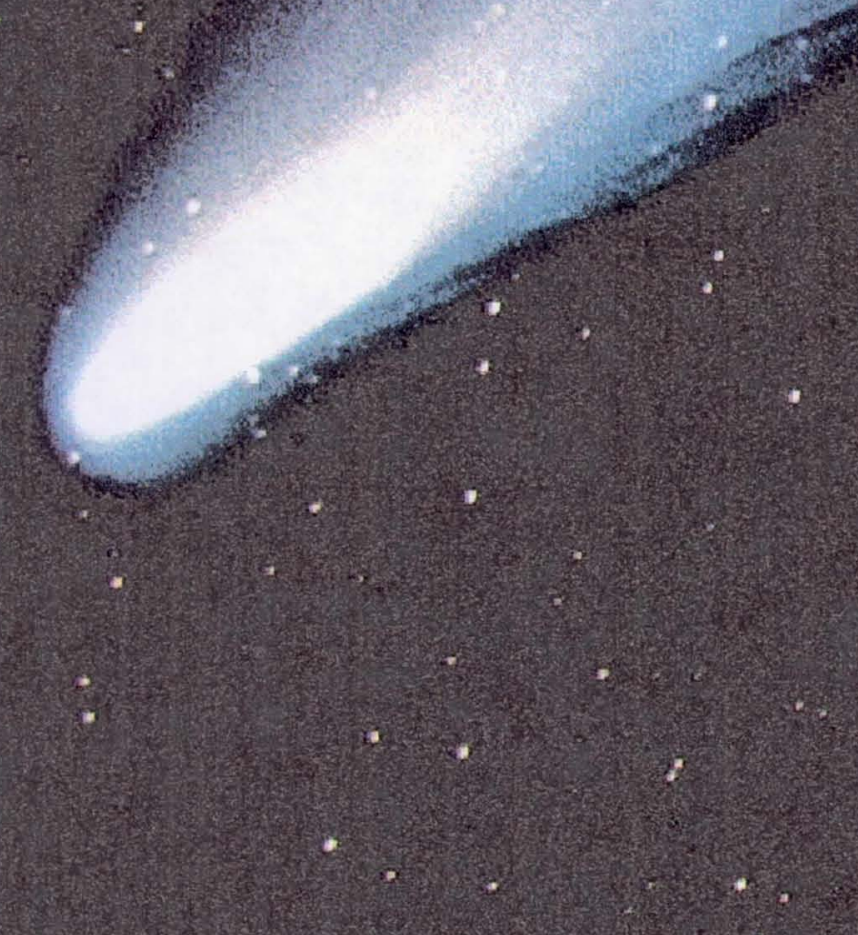

The Next Stepping Stone For Laser Technology in Space may:be the Deflection of Asteroids, Meteorojids, and Comets $\because$. 


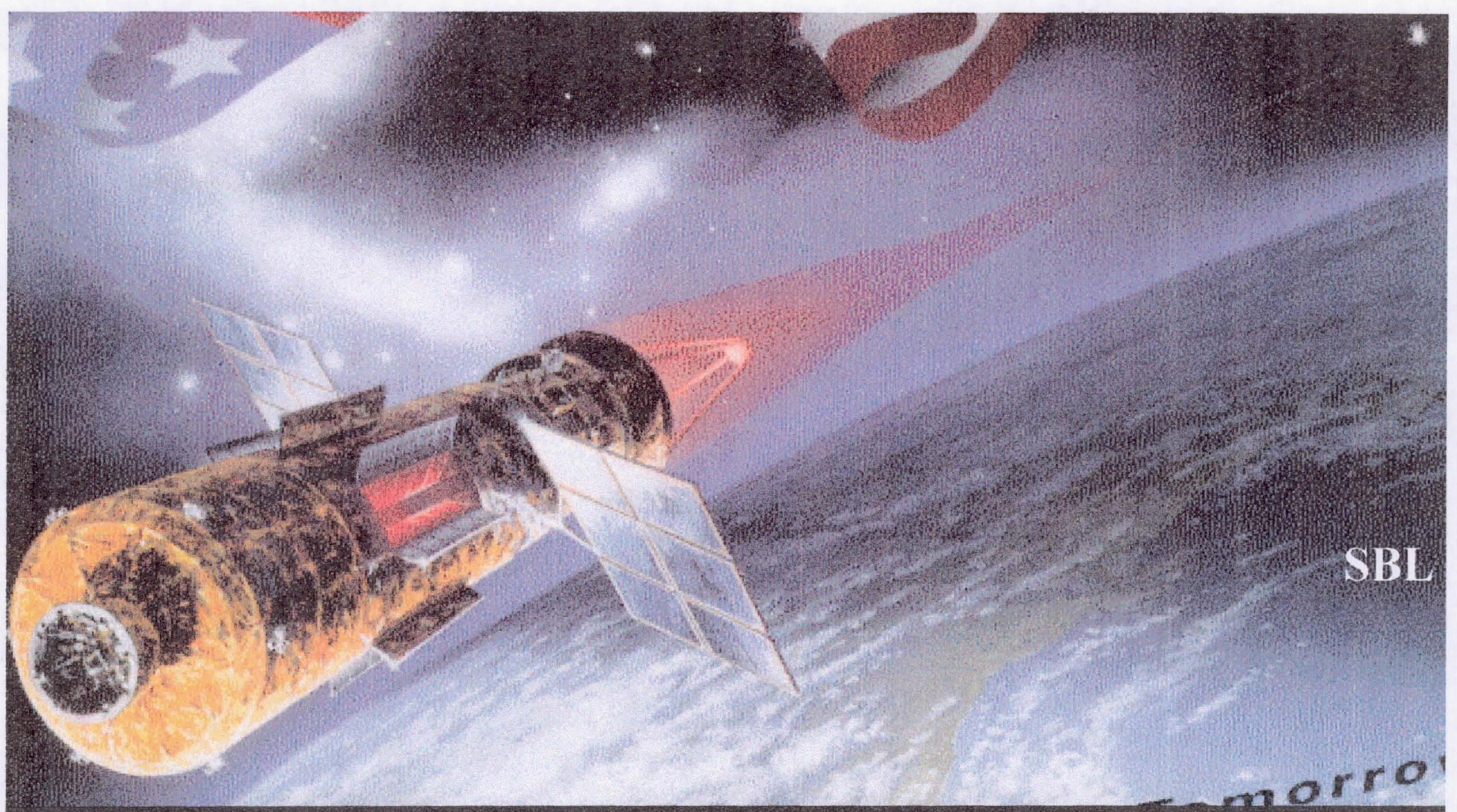

We Will See Laser Systems Deployed In Space In The Next Millenium To Defeat Missiles. Peacetime Missions Could Include Orbital Debris Removal And Comet, Asteroid, Meteoroid Deflection. 


\section{* Recent Missions}

have found water

in deep craters

at the lunar

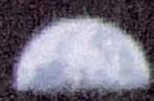

poles

* Technology

can be

derveloporat tro

reclaim this

Water for use

in permanent

frathices and to

make rocket fuel

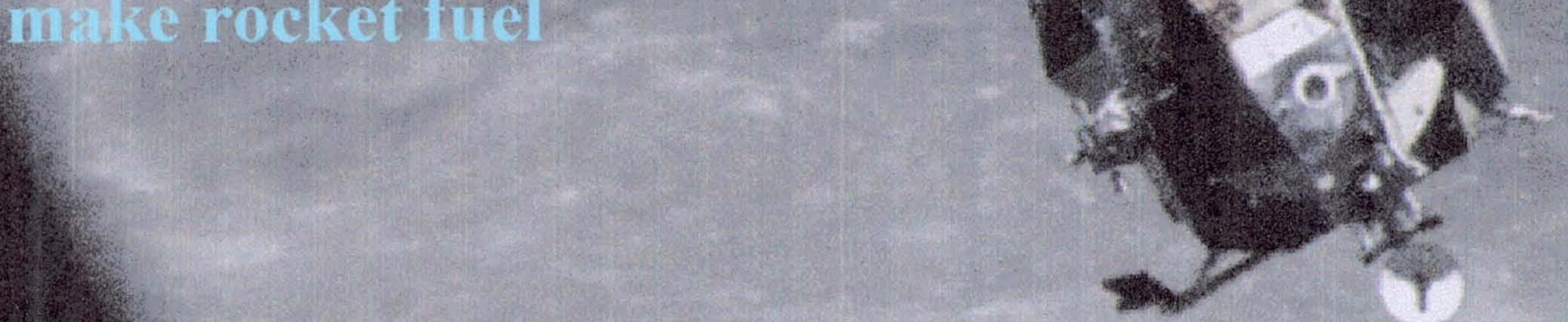




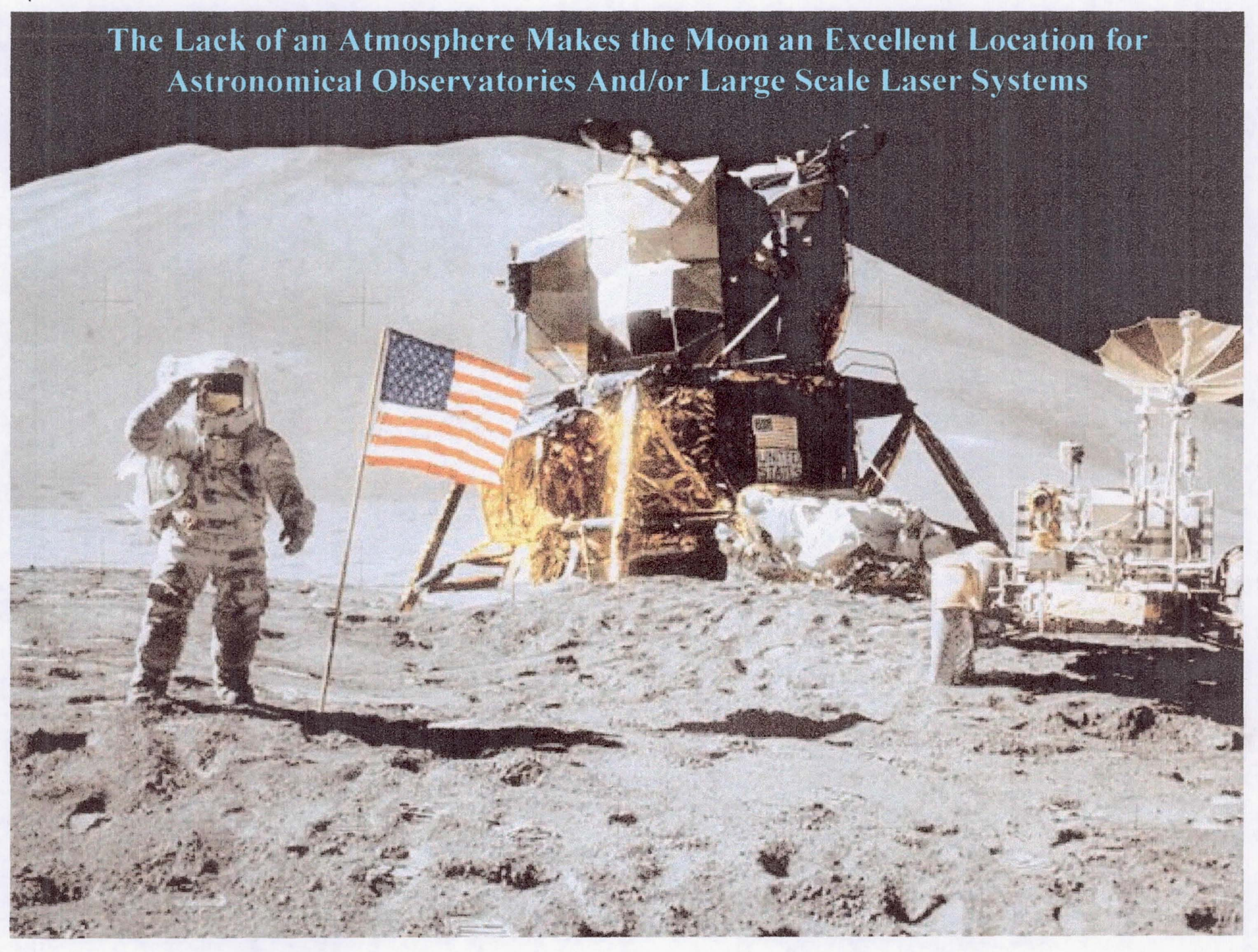




\section{THE MOON OFFERS SIGNIFICANT INFRASTRUCTURE ADVANTAGES}

- Array of telescopes ladar, and radar on moon, in orbit, and.or at Libration points

- No atmospheric distortion

- Better prediction capabilities

- Wider range of wavelength detection

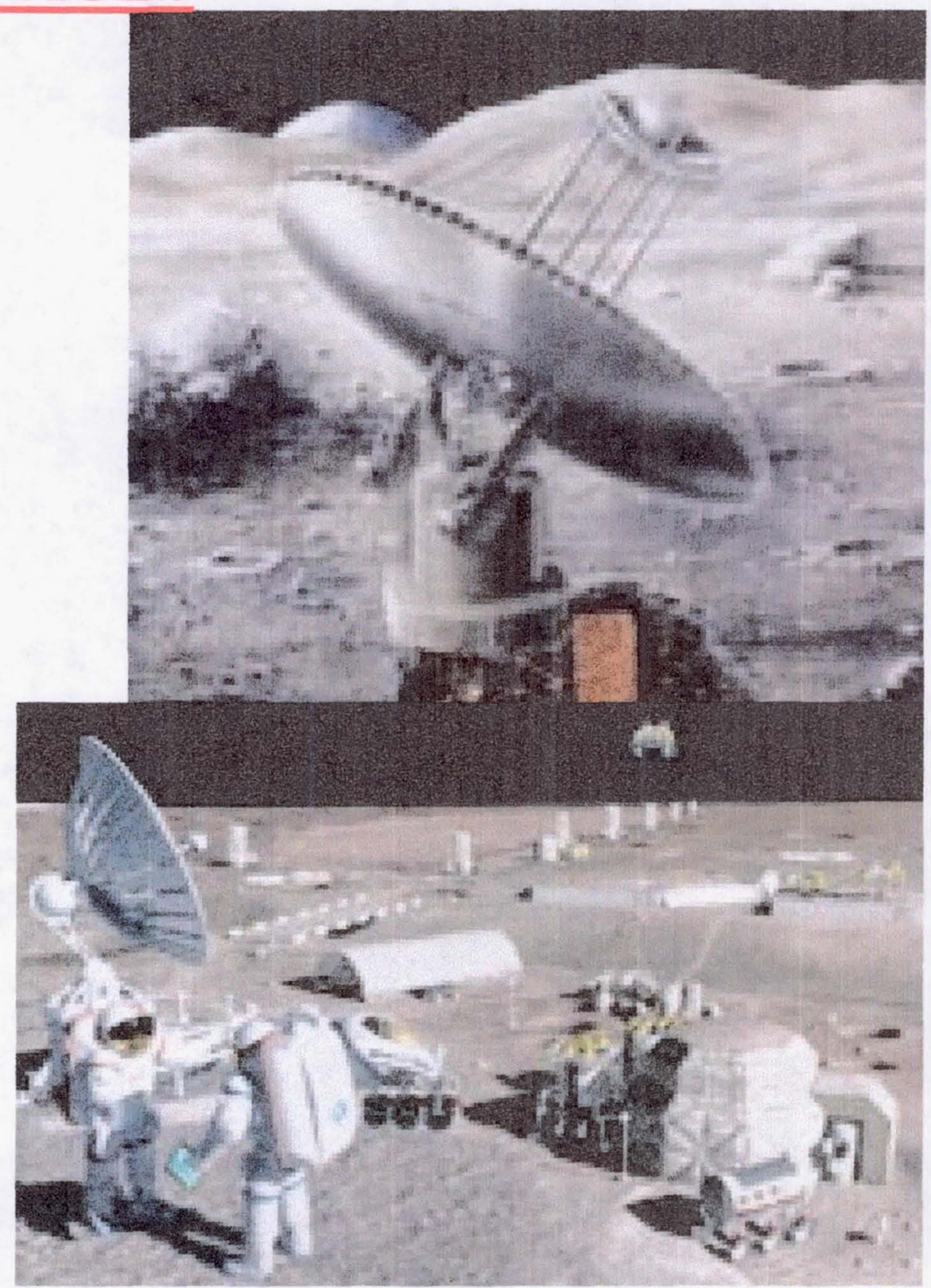




\section{Earth Defense Laser Scenario}

- Beam hits surface, ablation occurs

- Sputters material off - action/reaction occurs

- rocket effect causes small change in orbit

- many such interactions over a sufficient period of time propel object clear of Earth

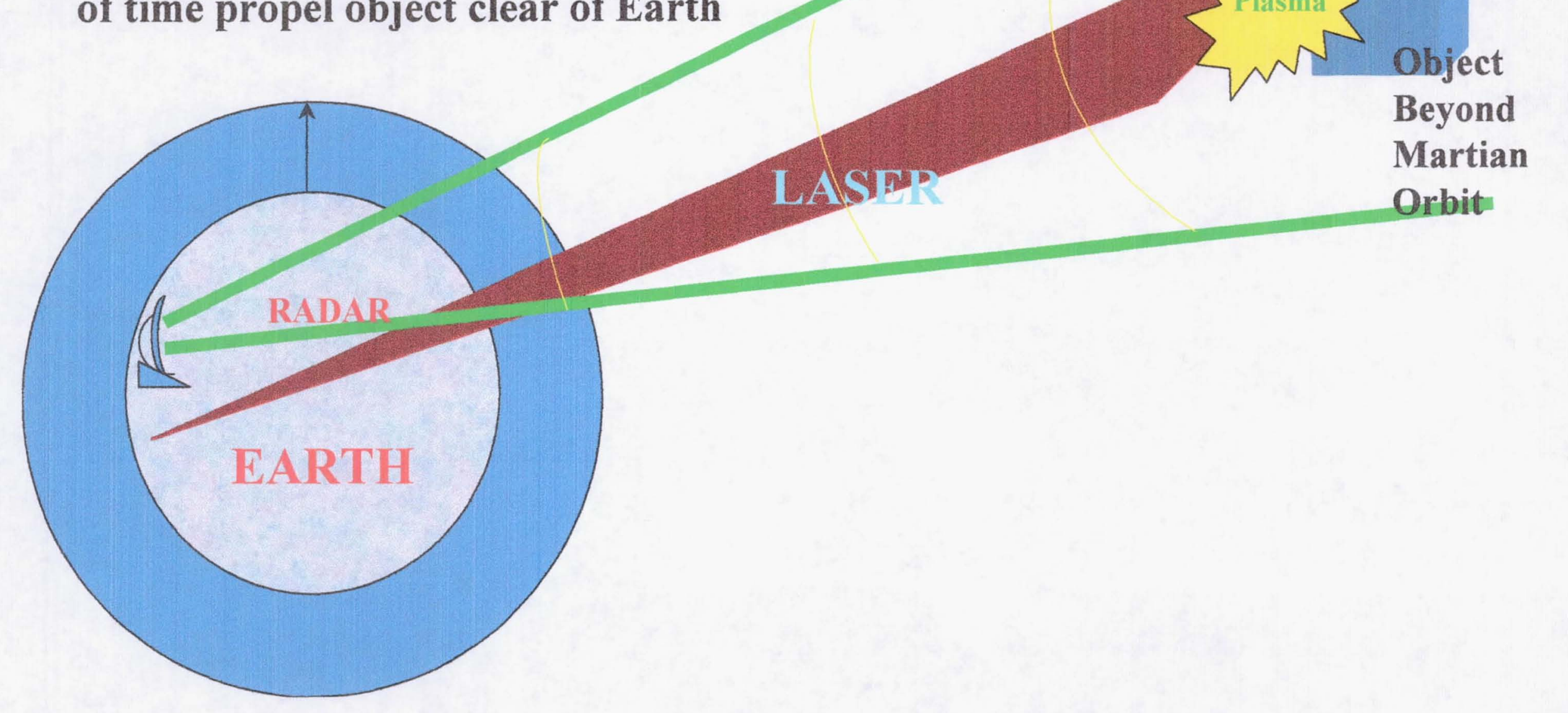




\section{Earth/LEO Option}

ORBITAL \& IMPULSE GEOMETRY

An Array of Multiple Laser Beam

Directors Operating For $\sim 1$ Month Was Sufficient to Deflect a One Kilometer Iron Asteroid in this Orbital Mechanics Simulation.

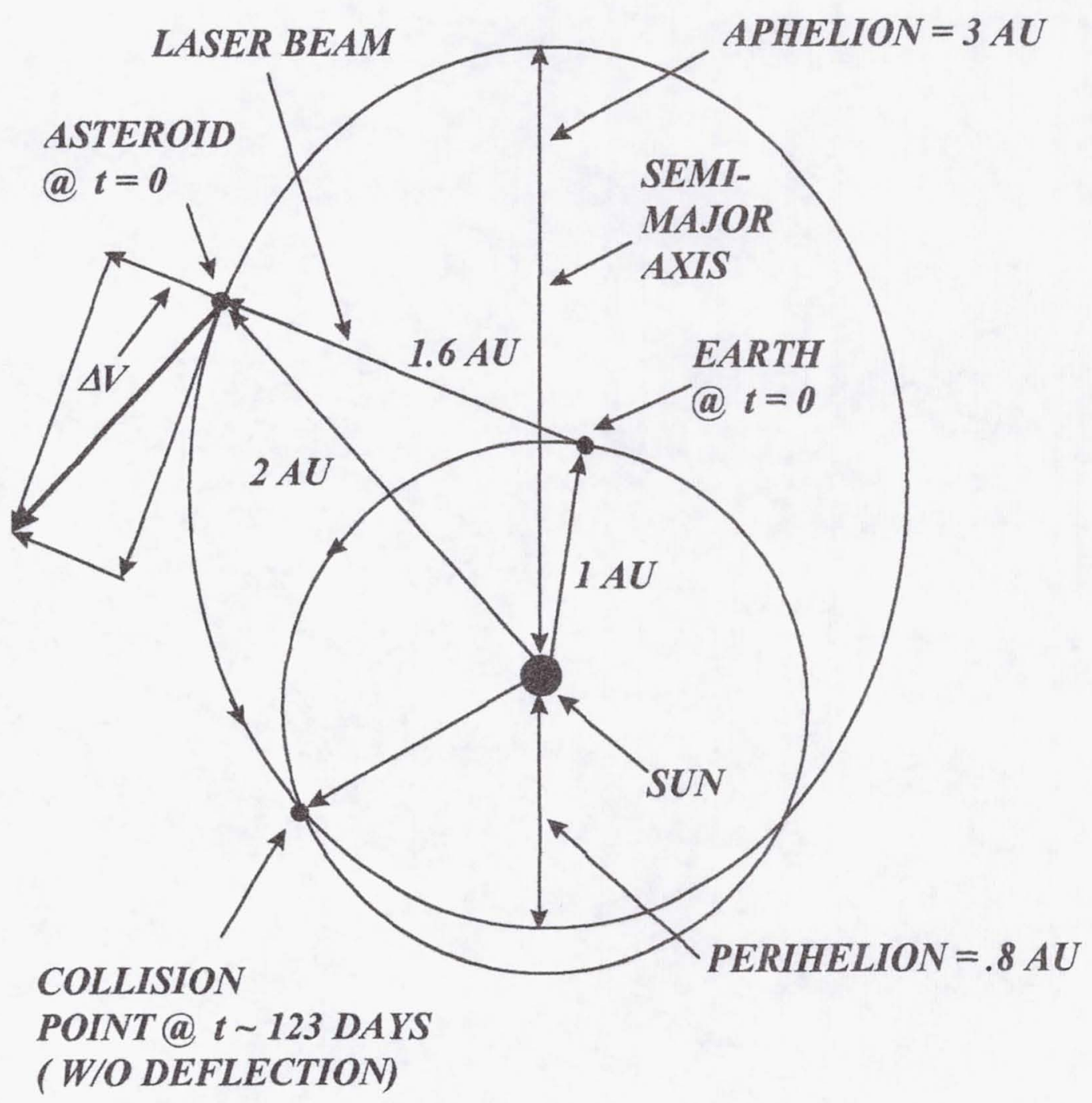




\section{Libration Point Option}

An Array of Multiple Laser Beam Directors Operating For $\sim 1$ Month Was Sufficient to Deflect a One Kilometer Iron Asteroid in this Orbital Mechanics Simulation.

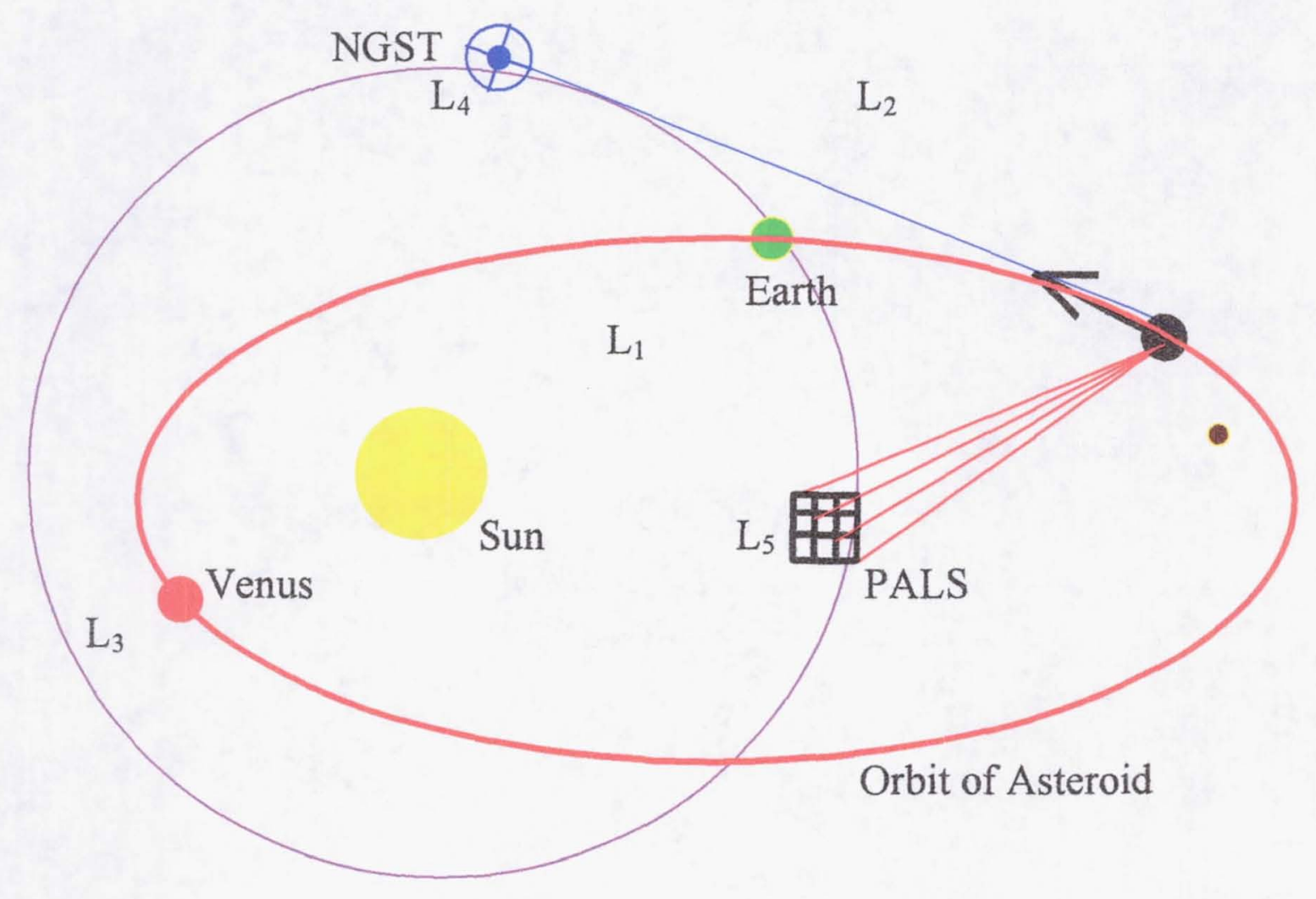

The five Lagrange points are shown as $L_{n}, n=1-5$. PALS is placed at $L_{5}$ and NGST is placed at $\mathrm{L}_{4}$. Note: nothing is to scale. 


\section{Lunar Option}

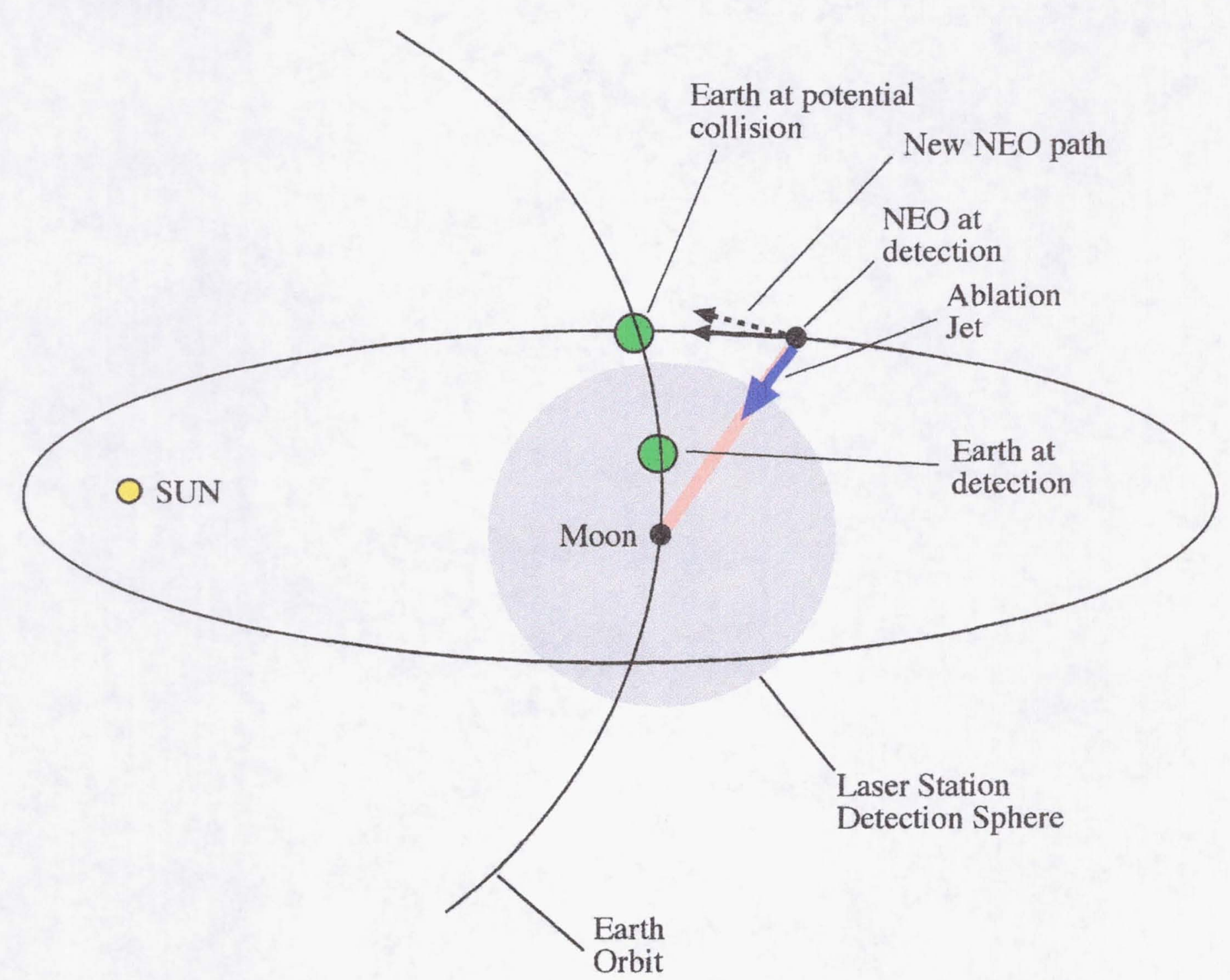

An Array of Multiple Laser Beam Directors Operating For 1 Month Was Sufficient to Deflect a One Kilometer Iron Asteroid in this Orbital Mechanics Simulation. 
Lateral displacement and final velocity of asteroid from original orbit per 2-D orbital mechanics simulation using expected coupling coefficients and state of the art laser intensities.

\begin{tabular}{|l|l|l|}
\hline $\begin{array}{l}\text { Time (in } \\
\text { days) }\end{array}$ & $\begin{array}{l}\text { Displaceme } \\
\text { nt } \\
\Delta \mathrm{R}\end{array}$ & $\begin{array}{l}\text { Final lateral } \\
\text { Velocity } v_{f}\end{array}$ \\
\hline $1.0 \mathrm{~d}$ & $4.9 \mathrm{~km}$ & $0.11 \mathrm{~m} / \mathrm{s}$ \\
\hline 10.0 & $485.0 \mathrm{~km}$ & $1.08 \mathrm{~m} / \mathrm{s}$ \\
\hline 36.0 & $1.00 \mathrm{R}_{\mathrm{E}}$ & $4.07 \mathrm{~km} / \mathrm{s}$ \\
\hline 38.8 & $1.10 \mathrm{R}_{\mathrm{E}}$ & $4.19 \mathrm{~km} / \mathrm{s}$ \\
\hline 44.0 & & \\
\hline 46.3 & $1.45 \mathrm{R}_{\mathrm{E}}$ & $4.75 \mathrm{~km} / \mathrm{s}$ \\
\hline & & \\
\hline & $1.56 \mathrm{R}_{\mathrm{E}}$ & $5.00 \mathrm{~km} / \mathrm{s}$ \\
\hline
\end{tabular}

The threshold for success in this simulation is derived to be deflecting the asteroid just outside the atmosphere. Due to the hypervelocity approach, the Earth's gravitational influence on the object is small. Hence, working on the object with the laser for $\mathbf{3 8 . 8}$ days is sufficient to guarantee the object does not impact the Earth. 


\section{INTERCEPTOR TECHNOLOGIES}

- Taking the laser to the object offers some advantages

- The interceptor may use a number of backup options as well to include nuclear ablation devices, electric propulsion, etc.

- Interceptor approaches require even greater early warning than near Earth lasers

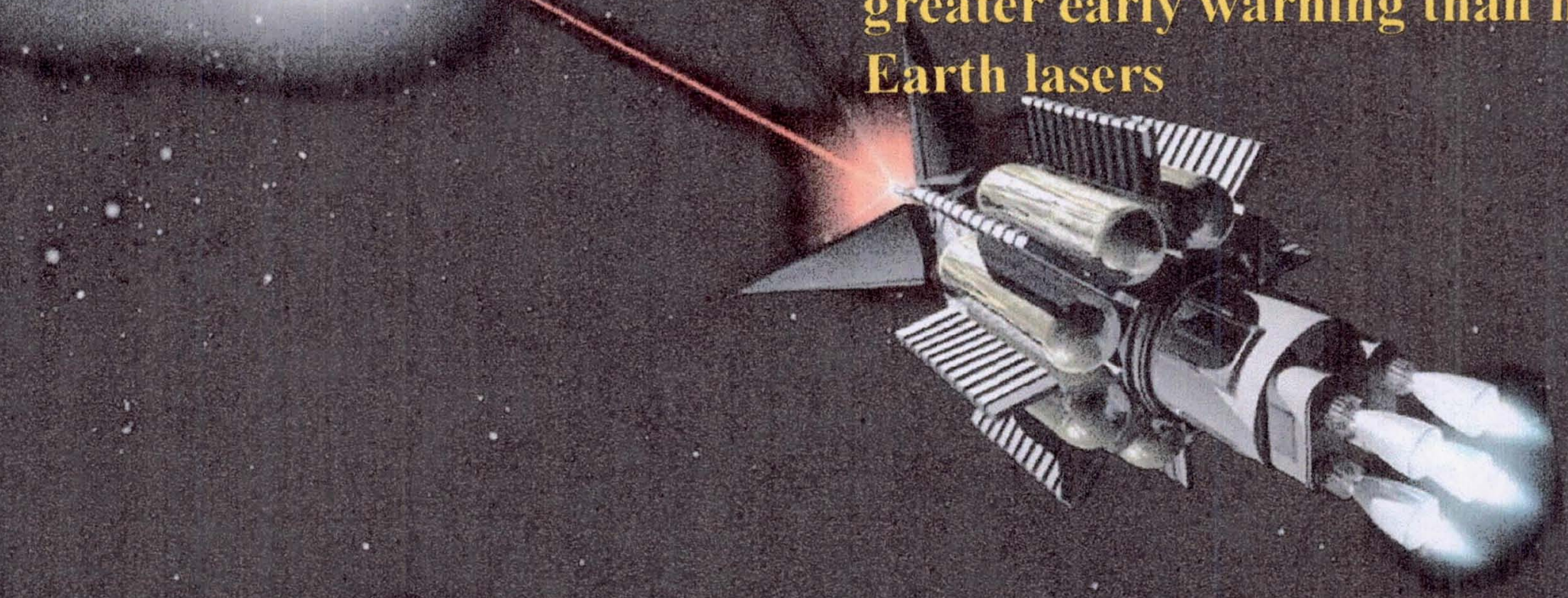




\section{SUMMARY AND CONCLUSIONS I}

$>$ Recent computational fluid dynamics (CFD) simulations have shown that relatively small objects (asteroids, meteoroids, comets) impacting the Earth at hypervelocities may cause large scale disasters.

Disasters similar to these have occurred multiple times in the past.

$>$ Orbiting the Sun, a substantive population of potential Earth impact objects exist in space. Many have not yet been found or their orbits calculated.

$>$ Detection capabilities are improving however we are still years away from finding and cataloging all potential Earth impactors.

$>$ Chaotic mechanisms in the asteroid belt, the Ort Cloud, and other locations in the solar system may be adding to the population. For example, asteroids impacting asteroids may force one into a potential impact orbit with the Earth.

$>$ Given sufficient early warning, technology should become available in the near future enabling orbit shaping of potential Earth impact objects allowing the avoidance of impact disasters. Moving the objects to convenient orbits around the Sun enables mining and in situ materials utilization.

$>$ Given the length of time necessary to develop capabilities in space, it is imperative that we begin immediately to build a multi-layered defense infrastructure to protect the Earth against impact. 


\section{SUMMARY AND CONCLUSIONS II}

Clearly this plan should be a series of overlapping steps starting with a comprehensive study, road mapping, planning and demonstration phase that should be begun immediately.

Also, Infrastructure building should start on the Earth with the acceleration of existing detection and tracking programs and the construction and/or dedication of an array of sensors to push early warning to years in advance.

$>$ Next, sensors and laser facilities must go into orbit constantly expanding capability and early warning time.

$>$ The moon is the next step with multiple stations for accomplishing the Earth defense role as well as supporting other objectives such as space science.

$>$ The libration points offer advantages as well.

$>$ An interceptor program must be considered as well. Taking the laser to the asteroid may offer some advantages. In addition, an interceptor could have a repertoire of approaches in addition to the laser such as nuclear ablation devices, nuclear electric thrusters, etc.

$>$ This challenge to our civilization's continued existence can only be addressed by doing everything we know how to do. Our protective shield must be $100 \%$ effective.

$>$ This is the IMPACT IMPERATIVE. 